\title{
Overview and sample applications of SMILES and Odin-SMR retrievals of upper tropospheric humidity and cloud ice mass
}

\author{
P. Eriksson ${ }^{1}$, B. Rydberg ${ }^{2}$, H. Sagawa ${ }^{3}$, M. S. Johnston ${ }^{1}$, and Y. Kasai ${ }^{3}$ \\ ${ }^{1}$ Department of Earth and Space Sciences, Chalmers University of Technology, 41296 Gothenburg, Sweden \\ ${ }^{2}$ Molflow, Gråbo Industriväg 8a, 44340 Gråbo, Sweden \\ ${ }^{3}$ National Institute of Information and Communications Technology, 4-2-1 Nukui-kitamachi, Koganei, Tokyo, Japan \\ Correspondence to: P. Eriksson (patrick.eriksson@ chalmers.se)
}

Received: 28 May 2014 - Published in Atmos. Chem. Phys. Discuss.: 14 August 2014

Revised: 16 October 2014 - Accepted: 28 October 2014 - Published: 1 December 2014

\begin{abstract}
Retrievals of cloud ice mass and humidity from the Superconducting Submillimeter-Wave Limb-Emission Sounder (SMILES) and the Odin-SMR (Sub-Millimetre Radiometer) limb sounder are presented and example applications of the data are given. SMILES data give an unprecedented view of the diurnal variation of cloud ice mass. Mean regional diurnal cycles are reported and compared to some global climate models. Some improvements in the models regarding diurnal timing and relative amplitude were noted, but the models' mean ice mass around $250 \mathrm{hPa}$ is still low compared to the observations. The influence of the ENSO (El Niño-Southern Oscillation) state on the upper troposphere is demonstrated using 12 years of Odin-SMR data.

The same retrieval scheme is applied for both sensors, and gives low systematic differences between the two data sets. A special feature of this Bayesian retrieval scheme, of Monte Carlo integration type, is that values are produced for all measurements but for some atmospheric states retrieved values only reflect a priori assumptions. However, this "allweather" capability allows a direct statistical comparison to model data, in contrast to many other satellite data sets. Another strength of the retrievals is the detailed treatment of "beam filling" that otherwise would cause large systematic biases for these passive cloud ice mass retrievals.

The main retrieval inputs are spectra around $635 / 525 \mathrm{GHz}$ from tangent altitudes below $8 / 9 \mathrm{~km}$ for SMILES/OdinSMR, respectively. For both sensors, the data cover the upper troposphere between $30^{\circ} \mathrm{S}$ and $30^{\circ} \mathrm{N}$. Humidity is reported as both relative humidity and volume mixing ratio. The vertical coverage of SMILES is restricted to a single layer, while Odin-SMR gives some profiling capability between 300 and
\end{abstract}

$150 \mathrm{hPa}$. Ice mass is given as the partial ice water path above $260 \mathrm{hPa}$, but for Odin-SMR ice water content, estimates are also provided. Besides a smaller contrast between most dry and wet cases, the agreement with Aura MLS (Microwave Limb Sounder) humidity data is good. In terms of tropical mean humidity, all three data sets agree within 3.5\%RHi. Mean ice mass is about a factor of 2 lower compared to CloudSat. This deviation is caused by the fact that different particle size distributions are assumed, combined with saturation and a priori influences in the SMILES and Odin-SMR data.

\section{Introduction}

Atmospheric ice particles constitute a key factor in earth's climate system for two main reasons. First, clouds consisting of such particles have a strong impact on the radiation balance. For example, the presence of high altitude ice clouds decreases the average outgoing long-wave radiation over extensive areas by $>40 \mathrm{Wm}^{-2}$, especially around the Intertropical Convergence Zone (see e.g. Hartmann, 1993). At night the resulting effect is a heating, while during day time the simultaneous increase in albedo causes a similar or even larger counteracting cooling effect. Hence, it is important to characterise and understand diurnal cycles in the processes generating these clouds. Second, ice particles are an essential part of the atmospheric water cycle, as, for example, they take part in the initiation of rain via the Bergeron process, and at higher altitudes ice can be a significant water reservoir (Ekström and Eriksson, 2008). To investigate the partitioning 
between gas and solid water in the atmosphere, simultaneous observations of the two phases are, of course, advantageous, but this capability is rarely found among present satellite retrievals.

A better understanding of the processes discussed above, including the associated validation of atmospheric models, requires global observations by satellites. The direct radiative impact of ice clouds is best quantified using measurements in the optical and infrared regions, because the main climatic radiative fluxes are found in these two wavelength regions. On the other hand, as cloud signatures in the optical and infrared regions are dominated by small particles in the top cloud layer, these measurements have limitations when determining total ice masses. Cloud penetration is achieved by microwave sensors, such as the CloudSat radar (Stephens et al., 2002), which is providing the first global measurements of ice water content.

CloudSat operates at $94 \mathrm{GHz}$. Sufficient sensitivity at this relatively low frequency can be obtained for active sounding. Passive measurements below $200 \mathrm{GHz}$ provide mainly detection of ice particles that can be classified as "snow" (see e.g. Evans and Stephens, 1995), whereas sensitivity to "cloud ice" particles requires shorter wavelengths. Accordingly, instruments dedicated to cloud ice mass retrieval that have channels above $200 \mathrm{GHz}$ have been proposed (Evans et al., 1999; Buehler et al., 2007). Following these mission proposals the Ice Cloud Imager (ICI) is now considered as an instrument for the second series of Metop satellites. ICI will extend the use of microwaves for operational observations by including channels up to $664 \mathrm{GHz}$ (D'Addio et al., 2014). A secondary objective of ICI is to improve on measurements of upper tropospheric water.

Satellite measurements at frequencies above $200 \mathrm{GHz}$ are not completely new. The wavelength region around $600 \mathrm{GHz}$ $(\lambda=0.5 \mathrm{~mm})$ has for some time been used for limb sounding by the Odin-SMR (Sub-Millimetre Radiometer; since 2001, Murtagh et al., 2002), Aura MLS (Microwave Limb Sounder; since 2004, Waters et al., 2006) and SMILES (2009-2010, Kikuchi et al., 2010) instruments. These limb sounders perform vertical scanning sequences where the tangent point is moved from about $100 \mathrm{~km}$ down to about $0 \mathrm{~km}$. Cloud ice mass retrievals have been presented for all three instruments (Wu et al., 2006; Eriksson et al., 2007; Millán et al., 2013). These retrievals change character around a tangent altitude of about $10 \mathrm{~km}$ (Wu et al., 2005; Eriksson et al., 2011b), and the range below this altitude limit is in this paper denoted as low tangent altitudes. In short, for high tangent altitudes, the radiative background is cold space and the presence of clouds results in higher brightness temperatures. On the other hand, for low tangent altitudes, clouds cause a decrease in brightness temperatures as they redirect comparably high emission from the lower troposphere.

This study considers the low tangent altitude data recorded by SMILES and Odin-SMR, and uses a common retrieval algorithm that provides combined estimates of humidity and ice water mass. This algorithm was introduced by Rydberg et al. (2009) and applied to Odin-SMR. For SMILES, earlier retrievals are restricted to Millán et al. (2013), who only reported ice masses using a less advanced retrieval methodology.

Both Odin-SMR and Aura MLS, as well as most existing space-based microwave radiometers, are in sun-synchronous orbits and thus produce observations at fixed local solar times. This gives poor coverage of diurnal variations. Data from different sensors have been combined to obtain better sampling of diurnal cycles (e.g. Eriksson et al., 2010), but this approach is very sensitive to differences in systematic errors of the sensors included. SMILES differs in this regard as it flew on the International Space Station (ISS). While this does not give an instantaneous full diurnal coverage, over some months the measurements inside a region are fairly equally distributed in local time over $24 \mathrm{~h}$. Hence, seasonally averaged diurnal cycles can be obtained by SMILES. In addition, SMILES employed superconducting technology to achieve very low noise and stable measurement data (Ochiai et al., 2013).

The objective of this paper is 2-fold. The first aim is to introduce the new SMILES data set, and at the same time provide updated results for Odin-SMR. Both these data sets are relatively small but complement other similar satellite measurements in regard to local time of measurements (particularly SMILES) and the length of the time series (OdinSMR). Agreement with the Aura MLS (relative humidity) and CloudSat (ice mass) data sets is analysed carefully. The second objective is simply to demonstrate that the SMILES and Odin-SMR retrievals are of interest for various applications. Emphasis is given to regional diurnal cycles of humidity and cloud ice mass, where some results from Eriksson et al. (2010) are assessed and updated. The impact of the ENSO (El Niño-Southern Oscillation) state on upper tropospheric humidity and ice mass is also considered.

\section{Satellite data}

\subsection{SMILES}

The SMILES onboard the ISS measured atmospheric emission around 625 and $650 \mathrm{GHz}$ from 12 October 2009 until 21 April 2010. SMILES was developed by the National Institute of Information and Communications Technology (NICT) and the Japan Aerospace Exploration Agency (JAXA). The main scientific objectives of SMILES were to obtain highly precise measurements of middle atmospheric minor constituents, such as $\mathrm{O}_{3}$ (including isotopologues), $\mathrm{HCl}, \mathrm{ClO}, \mathrm{HO}_{2}, \mathrm{BrO}$, $\mathrm{HNO}_{3}$, and $\mathrm{HOCl}$, and to determine the diurnal variation of these species. It was also known prior to launch that SMILES was sensitive to upper tropospheric humidity and ice clouds, but the instrument was not optimised for such observations. Kikuchi et al. (2010) provides an overview of the SMILES 
mission, Ochiai et al. (2013) gives an overview of the calibration of SMILES, and standard level 2 products are described by Takahashi et al. (2010) and Baron et al. (2011).

The inclination of the ISS orbit is $51.6^{\circ}$ to the equator, and ISS had at the time of SMILES's operation an altitude between 333 and $370 \mathrm{~km}$. SMILES measurements cover latitudes between approximately $38^{\circ} \mathrm{S}$ and $65^{\circ} \mathrm{N}$, but only measurements within $30^{\circ} \mathrm{S}$ to $30^{\circ} \mathrm{N}$ are considered for this study. A unique characteristic of the measurement coverage of SMILES is the local time variation. The local time of observations for a given region shifts by $24 \mathrm{~h}$ in about 2 months.

SMILES measured in three $1.2 \mathrm{GHz}$ wide frequency bands: 624.32-625.52 (Band A), 625.12-626.32 (Band B), and $649.12-650.32 \mathrm{GHz}$ (Band $\mathrm{C}$ ), but only two of them were measured simultaneously, with two acousto-optical spectrometers. Band combinations were altered on a timeshare basis. Frequencies selected for this study are presented in Table 1. The receiver noise temperature was about $350 \mathrm{~K}$. The size of the antenna beam at the tangent point was about 3 and $6 \mathrm{~km}$ in the vertical and horizontal directions, respectively. The scanning was performed from altitudes below the surface up to around $100 \mathrm{~km}$, at an angle of about $45^{\circ}$ from the orbital plane and with a repetition period of $53 \mathrm{~s}\left(\sim 1630\right.$ scans day $\left.^{-1}\right)$. The retrievals presented are based on individual spectra from the tangent heights between -30 and $8 \mathrm{~km}$. There is little overlap in covered air volume between the spectra, which is due to the out-of-orbit scanning. Tangent altitudes given neglect the impact of refraction. A negative value refers to a hypothetical tangent point below the surface.

SMILES L1b data used are of calibration version 008. In this version, the determination of both brightness temperatures and tangent heights has been improved compared to earlier versions (Ochiai et al., 2013). The tangent height accuracy is now about $140 \mathrm{~m}$, but occasionally the errors can be larger than $200 \mathrm{~m}$. The largest error source in the intensity calibration scheme is the gain non-linearity $(\sim 1 \mathrm{~K})$, which is well above the thermal noise level and is $\approx 0.15 \mathrm{~K}$ over the frequency bands selected. The SMILES level 2 data introduced in this article, as well as further documentation (Kasai et al., 2014), can be downloaded from smiles.nict.go.jp/pub/ data/.

\subsection{Odin-SMR}

When launched in 2001, SMR became the first satellite instrument to observe our atmosphere in the frequency range above $300 \mathrm{GHz}$. Murtagh et al. (2002) give an overview of Odin's atmospheric mission, and the performance of the SMR instrument regarding its standard stratospheric and mesospheric retrievals is summarised by Merino et al. (2002). The measurements used for these retrievals and the most relevant technical details are presented in Ekström et al. (2007) and Eriksson et al. (2007). These two articles describe version 1 of the retrievals. Version 2.0 was introduced
Table 1. SMILES and SMR frequency bands used expressed in GHz. Radiative transfer calculations are performed only for the centre frequency, while the measured radiances are averaged over the ranges specified.

\begin{tabular}{lcc}
\hline Sensor & Frequency & Band name \\
\hline \multirow{3}{*}{ SMILES } & $624.61 \pm 0.005$ & $\mathrm{~A}$ \\
& $626.23 \pm 0.005$ & $\mathrm{~B}$ \\
& $649.61 \pm 0.005$ & $\mathrm{C}$ \\
\hline SMR & $501.38 \pm 0.20$ & 1 \\
& $544.43 \pm 0.10$ & 2 \\
\hline
\end{tabular}

by Rydberg et al. (2009). The present version is 2.1, and these SMR retrievals are available at odin.rss.chalmers.se/ special-datasets.

Odin is in a sun-synchronous orbit with an altitude of about $600 \mathrm{~km}$ and an ascending node around 18:00 h (local solar time). SMR has four receiver chains operating at frequencies between 486 and $581 \mathrm{GHz}$. The two autocorrelator spectrometers give an instantaneous frequency coverage of $1.6 \mathrm{GHz}$. A number of observation modes are applied to observe all spectroscopic features of interest. For these retrievals, only data from the "stratospheric mode", frequency modes 1 and 2, are used. Exact frequencies are found in Table 1. The size of the antenna beam at the tangent point is about $2 \mathrm{~km}$ in both the vertical and horizontal directions. Odin scans the atmosphere by a rotation of the complete platform, measuring during both downward and upward directions. A scan sequence from mesospheric altitudes down to $0 \mathrm{~km}$ and back takes about $250 \mathrm{~s}$. The retrievals presented use single spectra for tangent altitudes below $9 \mathrm{~km}$. Due to the scanning pattern, such spectra are found in groups covering partly overlapping air volumes. These groups of spectra are separated by about $250 \mathrm{~s}$ (or $\sim 2000 \mathrm{~km}$ horizontally). In addition, the stratospheric mode is operated only roughly $30 \%$ of the time. This gives in total a relatively low data volume. On the other hand, the Odin satellite has a long time coverage: it has been operational for over 12 years. The results presented cover the period 1 January 2002 to 31 December 2013.

\subsection{CloudSat}

CloudSat, launched in 2006, carries the first space-based cloud radar. Sensitivity to cloud ice and liquid particles is achieved by using a higher frequency, $94 \mathrm{GHz}$, compared to radars targeting precipitation. The footprint of the radar has a diameter around $1.5 \mathrm{~km}$, and the vertical resolution is $500 \mathrm{~m}$. No across-track scanning is performed. See Stephens et al. (2002) for further technical details. The CloudSat 2B-CWCRO retrieval product (Austin et al., 2009) was selected for this study. This data set is solely based on the CloudSat radar, which is an advantage as it gives a sensitivity with respect 
to ice particle sizes similar to the one for SMR and SMILES (Eriksson et al., 2008). The 2B-CWC-RO can be downloaded from www.cloudsat.cira.colostate.edu. CloudSat is at present performing measurements only during daylight conditions, due to a battery failure in 2011 , but is otherwise fully functional.

\subsection{Aura MLS}

Aura MLS is to date the most ambitious microwave limb sounding mission, covering frequency bands around 118, 190, 240, 640 and $2500 \mathrm{GHz}$ (Waters et al., 2006). The Aura satellite was launched in 2004 and MLS is still in operation. Aura, as well as CloudSat, is part of the A-train satellite constellation. Among all MLS retrieval quantities, only the relative humidity product is used in this study. An introduction to the data set can be found at mls.jpl.nasa.gov/products/rhi_ product.php, and detailed information is given by Read et al. (2007). The vertical resolution of these retrievals is roughly $4 \mathrm{~km}$, and the along-track resolution $\sim 200 \mathrm{~km}$. For altitudes around $200 \mathrm{hPa}$, the systematic errors are estimated to $30 \%$ (a relative value). The data were quality filtered according to instructions in the associated documentation.

\section{The retrievals}

\subsection{Quantities}

The target of the retrievals is atmospheric water, in both its gaseous and ice phases. Water vapour is primarily retrieved as the relative humidity with respect to ice, in percent (\% RHi), but volume mixing ratio (ppm) retrievals are also considered. Cloud ice mass is reported throughout the paper as partial ice water paths (pIWPs; $\mathrm{g} \mathrm{m}^{-2}$ ). That is, the vertical integral of the ice water content (IWC; $\mathrm{g} \mathrm{m}^{-3}$ ) above some altitude is given. Two altitude limits are used, $260 \mathrm{hPa}$ and $12.5 \mathrm{~km}$, with the corresponding column values denoted as pIWP $260 \mathrm{hPa}$ and $\mathrm{pIWP}_{12.5 \mathrm{~km}}$, respectively.

\subsection{Method}

Rydberg et al. (2009) applied a Bayesian inversion strategy, where the solution is found by Monte Carlo integration (MCI) using a "retrieval database". More precisely, the retrieved state vector, $\hat{\boldsymbol{x}}$, is calculated as (Evans et al., 1995; Kummerow et al., 1996)

$\hat{\boldsymbol{x}}=\frac{\sum_{i=1}^{n} w_{i} \boldsymbol{x}_{i}}{\sum_{i=1}^{n} w_{i}}$

where $n$ is the size of the database and $\boldsymbol{x}_{i}$ is the state vector for each case in the database. The weights, $w_{i}$, can be seen as (non-normalised) a posteriori probabilities for each database case. These are calculated as

$w_{i}=\exp \left(-\frac{\left(\boldsymbol{y}-\boldsymbol{y}_{i}\right)^{T} \mathbf{S}_{\mathrm{e}}^{-1}\left(\boldsymbol{y}-\boldsymbol{y}_{i}\right)}{2}\right)$, where $\boldsymbol{y}$ is the measurement to be inverted, $\boldsymbol{y}_{i}$ is the simulated measurement for database case $i$ and $\mathbf{S}_{\mathrm{e}}$ is the covariance matrix of observational errors. This general retrieval approach is commonly applied for microwave precipitation retrievals (e.g. Petty and Li, 2013).

The same database is applied for both humidity and ice mass, and it contains simulations covering both "clear-sky" and "cloudy" conditions. The measurement vector $\boldsymbol{y}$ is discussed for each sensor below. The MCI method is very flexible with regard to the state vector $(\boldsymbol{x})$; for example, it can include the same quantity expressed in several units simultaneously with very little extra calculation burden. In our implementation all quantities of interest are retrieved in parallel. More precisely, the state vector contains the vertical profile of humidity, in both \% RHi and volume mixing ratio, and the vertical profile of ice water content, as well as $\mathrm{pIWP}_{260 \mathrm{hPa}}$. For Odin-SMR also pIWP $12.5 \mathrm{~km}$ is appended to $\boldsymbol{x}$.

For MCI, the inversion performance is largely determined by how closely the database mimics the conditions of the real atmosphere. In this context, the main challenge is to incorporate realistic cloud structures in the database. The retrievals can be performed without any a priori information about vertical cloud correlations (Eriksson et al., 2007), but such information is still beneficial. Much more critical is a priori knowledge of horizontal structures to decrease any systematic impact of "beam filling" (see e.g. Davis et al., 2007). The origin to the beam filling effect is horizontal inhomogeneity of the cloud field inside the footprint, but the final effect of beam filling depends on the degree of non-linearity between the cloud variables and changes in radiance. If horizontally homogeneous cloud fields are assumed, the beam filling results in that cloud mass retrievals systematically underestimate the corresponding true footprint averaged value. This is the case as if some amount of ice is gathered in a small volume; this gives a smaller impact on measured brightness temperature than if the same ice mass is evenly distributed over the sensor's footprint.

The beam filling problem is decreased by incorporating CloudSat observations. Three-dimensional cloud fields are created from the CloudSat 2-D soundings by a stochastic method assuming horizontally isotropic statistics (Venema et al., 2006). This approach in combination with the limb sounding geometry imposes a constraint on a forward model capable of handling 3-D radiative transfer in a spherical geometry. This is handled by version 2 of ARTS (Atmospheric Radiative Transfer System, Eriksson et al., 2011a). ARTS is applied using the reversed Monte Carlo scattering (Davis et al., 2005) and absorption lookup (Buehler et al., 2011) modules. That is, series of CloudSat profiles of backscattering data form the basis to generate local 3-D atmospheric scenarios. For each such scenario, Odin-SMR and SMILES measurements are simulated, considering both vertical and horizontal structures in the atmosphere by performing 3-D radiative transfer. The retrieval database contains simulations for 12040 scenarios. CloudSat data were picked randomly 
between $30^{\circ} \mathrm{S}$ and $30^{\circ} \mathrm{N}$ and, accordingly, the database aims at reflecting the true atmospheric variability inside the Tropics. Radiative transfer calculations are only performed for the centre frequencies listed in Table 1, while the satellite observations are averaged over the frequency ranges to decrease the impact of thermal noise. The vertical variation of the antenna response (integrated in the azimuth dimension) is considered.

No CloudSat retrievals are involved: it is the basic observation of backscattering that forms the basis for the final 3-D cloud fields. These 3-D fields are converted to radiative properties (i.e. single scattering properties) by assuming all particles to be solid ice spheres and that the particle size distribution follows the parameterisation derived by McFarquhar and Heymsfield (1997). However, these steps result in an alternative ice water content retrieval, which is used in Sect. 4.2.1.

\subsection{Special considerations for Odin-SMR}

As in Rydberg et al. (2009), the measurement vector ( $\boldsymbol{y}$ in Eq. 2) has four elements. The first two elements are the brightness temperatures at 501.38 and $544.43 \mathrm{GHz}$ (Table 1). The corresponding variance in $\mathbf{S}_{\mathrm{e}}$ is for $501.38 \mathrm{GHz}$ set to $2^{2} \mathrm{~K}^{2}$, and for $544.43 \mathrm{GHz}$ it is set to $3.5^{2}$ or $2.5^{2} \mathrm{~K}^{2}$, depending on integration time. Ideally, these variances should follow the thermal noise (and would then be much lower), but for frequency averaged SMR data they are mainly determined by remaining effects of gain variations.

The satellite pointing obtained from attitude data is treated as a measurement and is inserted as element three in $\boldsymbol{y}$. In terms of tangent altitude, the uncertainty of the pointing is assumed to have a standard deviation $(1 \sigma)$ of $200 \mathrm{~m}$. The temperature at the point where the satellite line-of-sight passes $200 \mathrm{hPa}$ is used as an external measurement. The temperature is taken from the European Centre for Medium-Range Weather Forecasts' (ECMWF) analysis and is assumed to have an uncertainty of $1 \mathrm{~K}(1 \sigma)$. The matrix $\mathbf{S}_{\mathrm{e}}$ is set to be diagonal, i.e. the observational errors are assumed to be uncorrelated.

A rough relation between cloud types and measured brightness temperatures is included in Fig. 1. In Rydberg et al. (2009) vertical profiles of \%RHi and IWC were retrieved. These quantities are still produced, but are not considered in this paper. Instead the SMILES retrieval products (see below) were added to the output. These retrievals are obtained as a direct output from MCI (not through a postprocessing of the \% RHi and IWC profiles).

The main difference between Rydberg et al. (2009) and this version of the Odin-SMR retrievals is that a new version of L1b data is used. SMR has an internal hot load target used for calibration. This target is observed at the upper and lower end points of the vertical scans. Consequently, a calibration observation is performed in the middle of each group of spectra used here. The movement of an internal mirror can affect the calibration, with a negative impact on final atmospheric spectra. Compared to the previous L1b version, a more adequate and standardised removal of spectra that are possibly affected by the mirror movement is now performed. The software also provides more information about the calibration of each spectrum, thereby providing a basis for additional quality filtering.

A strong ozone transition $(544.86 \mathrm{GHz})$ in the frequency mode 2 band allows further quality filtering. For the tangent altitudes considered in this study, the brightness temperature around the centre of this transition shows relatively small variations. This is a consequence of several factors, including that this part of frequency mode 2 is not affected by tropospheric clouds due to high ozone absorption in the stratosphere. As a consequence, the transition allows one to check that spectra have radiances of expected magnitude. Further details of this filtering approach are found in Kasai et al. (2014).

All remaining data are kept, giving 0.68 million retrievals for the period 2002-2013. Versions 2.1 and 2.0 of the retrievals agree closely with respect to mean values. Differences are limited to a smaller set of individual data points.

\subsection{Special considerations for SMILES}

For a more detailed discussion we refer to Kasai et al. (2014). This theoretical basis document is found at the same web site as the SMILES level 2 data (see Sect. 2.1).

For tropospheric altitudes, the measurement information within the SMILES bands is highly correlated. The centre panel of Fig. 1 shows that the brightness temperatures of bands A and B are almost identical. This is not surprising, as the band $\mathrm{A}$ and $\mathrm{B}$ frequencies are separated by less than $2 \mathrm{GHz}$, and are not close to any significant water vapour transition. Hence, the two bands provide basically identical information. Some differences are found between bands $\mathrm{A}$ and $\mathrm{C}$ (Fig. 1, right panel). The main reason for the differences is that the sensitivity of band $\mathrm{C}$ is shifted downwards in altitude by about $500 \mathrm{~m}$. The fact that the scattering is stronger in band $\mathrm{C}$, having a higher frequency, can also be involved. This means that band $\mathrm{C}$ together with band $\mathrm{A}$ or $\mathrm{B}(\mathrm{A}+\mathrm{C}$ or $\mathrm{B}+\mathrm{C}$ ) gives more information than $\mathrm{A}+\mathrm{B}$, or any of the bands alone, but still less than provided by the two SMR frequencies.

Simulations were performed to identify suitable retrieval parameters. It was confirmed that there is no basis for profile retrievals. Instead, it was judged that the column ice mass above $260 \mathrm{hPa}\left(\mathrm{pIWP}_{260 \mathrm{hPa}}\right)$ and the mean relative humidity (\%RHi) between 260 and $200 \mathrm{hPa}$ are the most suitable parameters for these SMILES data.

The retrieval database was created from the same 3-D atmospheric scenarios as used for SMR and the same overall calculation procedure was applied. The size of the 3-D scenarios was selected originally to just cover simulations of tangent altitudes between -5 and $14 \mathrm{~km}$ from a single sensor position (the propagation path of lower and higher tangent 

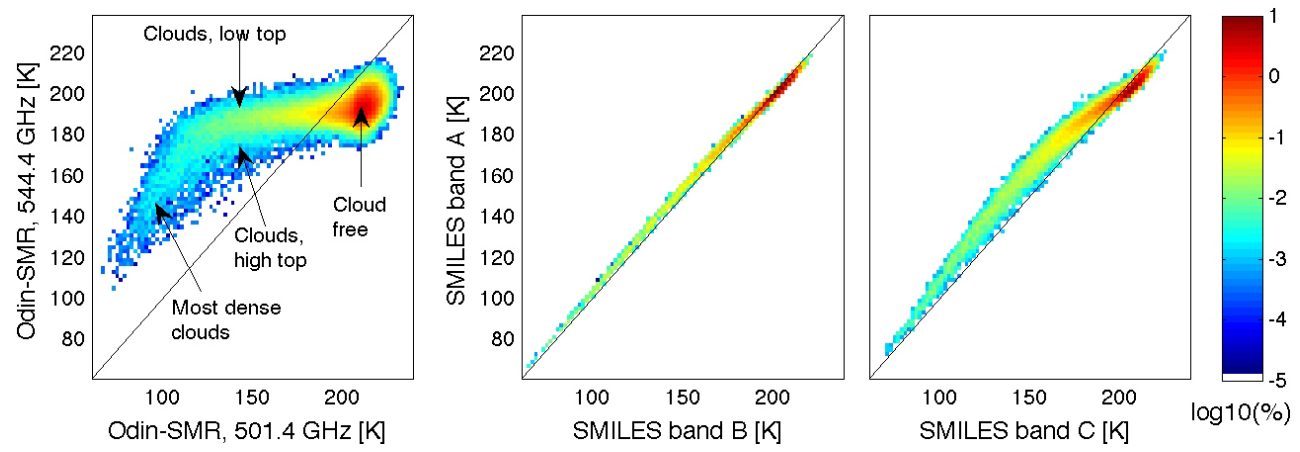

Figure 1. Bivariate distributions of SMR (left) and SMILES (centre and right) measured brightness temperatures. Data for tangent altitudes between 3 and $8 \mathrm{~km}$ are included.

altitudes ends up outside the atmospheric volume having detailed 3-D data). As SMILES covers a wider tangent height range ( -30 to $8 \mathrm{~km}$ considered here) than SMR, it was necessary to perform simulations from different sensor positions, and for practical reasons the simplest solution was then to form three retrieval databases, each applicable for a range of tangent altitudes: -30 to $-4,-4$ to 4 , and 4 to $8 \mathrm{~km}$, respectively. The relatively small size of the two uppermost altitude ranges is a consequence of the fact that the antenna pattern has a vertical extension and that the databases must also contain spectra for tangent altitudes outside the nominal range. At each simulation position, SMILES is placed $350 \mathrm{~km}$ above ground. The gas species included in the forward model calculations are $\mathrm{H}_{2} \mathrm{O}, \mathrm{N}_{2}, \mathrm{~N}_{2} \mathrm{O}, \mathrm{O}_{2}, \mathrm{O}_{3}, \mathrm{ClO}$, and $\mathrm{HNO}_{3}$.

The measurement vector and its covariance matrix, to be applied in Eq. (2), are almost identical to the ones for SMR. The first two elements are the brightness temperatures from two SMILES bands. The estimated uncertainty for these values is $1 \mathrm{~K}(1 \sigma)$. The third and fourth elements are treated exactly as for SMR.

The spectra are quality filtered using several variables that are part of the L1b data. As for SMR, an ozone transition is also used to identify erroneous data. The ozone transition is found at $625.37 \mathrm{GHz}$, a frequency covered by both bands A and B. However, this ozone transition has a lower optical thickness than the one used for SMR, and the filtering must consider some influence from tropospheric altitudes. Spectra removed by this quality check are judged to correspond to outliers in determination of the pointing.

\subsection{Error estimates}

\subsubsection{Relative humidity}

The errors of SMR relative humidity data are estimated and discussed in Ekström et al. (2007) and Rydberg et al. (2009). This is repeated for SMILES in Kasai et al. (2014). This section is a summary that focuses on SMILES. The humidity data displayed in this paper are best estimates of the mean
$\%$ RHi between 260 and $200 \mathrm{hPa}$, but the actual vertical resolution is about $5 \mathrm{~km}$ (Rydberg et al., 2009).

The precision of SMILES is around $10 \% \mathrm{RHi}$, or $15 \%$ in relative terms, for values around $70 \%$. This is around a factor of two better than SMR. The systematic error (root sum square) of SMILES was estimated to be better than $12 \%$ RHi for relative humidities of $70 \%$ and below. The error in the \%RHi product depends mainly on accuracy of the calibration (intensity and pointing) and the spectroscopic setup of the forward model simulations. A statistical comparison between clear-sky simulations for the states in the retrieval database and real measurements for SMILES indicated an agreement better than $1 \mathrm{~K}$. An effective $1 \mathrm{~K}$ error translates into $\mathrm{a} \sim 10 \%$ RHi systematic error. In addition, for both SMILES and SMR the usage of a priori impacts on the accuracy of the retrieval, as values are biased towards the retrieval database mean. This effect is largest for high \% RHi values. For relative humidities around $120 \%$ retrieved values are underestimated by $20 \%$ RHi. However, for averaged data this error can be reduced as described in Rydberg et al. (2009).

\subsubsection{Partial IWP}

The SMR and SMILES pIWP observations are very similar, and so are the estimated errors. Kasai et al. (2014) analyse the errors of the SMILES pIWP, and these results are also valid for pIWP from SMR. Errors for other SMR cloud ice data are estimated and discussed in Eriksson et al. (2007) and Rydberg et al. (2009). In all cases, the errors have been estimated by performing radiative transfer calculations, or by making test inversions using simulated measurements. The errors are reported as relative values with respect to expectation value.

pIWP $260 \mathrm{hPa}$ is a measure of the amount of cloud ice mass above $260 \mathrm{hPa}$ within the sampled volume, converted to a vertical column value. The estimated precision (root sum square) for SMR and SMILES is around $70 \%$ for this quantity and for values above a few $\mathrm{g} \mathrm{m}^{-2}$. The main error sources are related to the natural variability of cloud particle size dis- 
tribution (PSD, $\sim 40 \%$ error) and particle shape, or single scattering properties (SSP, $\sim 15 \%$ error), and cloud structure variability within the sampled volume (beam-filling problem, $\sim 40 \%$ ).

The estimated systematic error for the pIWP product is around $40 \%$. One part of this error comes from the assumed PSD $(\sim 30 \%$ error $)$ and particle ensemble SSP $(\sim 15 \%$ error) in the atmospheric states of the retrieval database (Rydberg et al., 2009), and how well these assumptions match the average tropical conditions. A second error source is related to the beam-filling problem. Cloud inhomogeneities are incorporated into the retrieval algorithm, but it is also likely that the effects are not fully captured $(\sim 15 \%)$. A third error comes from the a priori usage which biases the retrieval towards the a priori mean ( $\sim 20 \%$ error). For most high pIWP, above $\sim 1000 \mathrm{~g} \mathrm{~m}^{-2}$, the retrievals have a strong low bias that is not yet fully understood, but it is likely caused by a saturation effect in the observations, which does not occur in the simulations due to incorrect assumptions on PSD and particle shape.

\section{Results and discussion}

SMILES was operational between 12 October 2009 and 21 April 2010. Unless otherwise stated, MLS and CloudSat data are taken from this time period of about 6 months, and only SMILES band combinations $\mathrm{A}+\mathrm{C}$ and $\mathrm{B}+\mathrm{C}$ are included. To obtain more stable results for SMR, i.e. to compensate for its low sampling rate, data between 12 October and 21 April for all years available are merged. This option is also used for MLS in some figures.

The properties of the SMR observations are explored by Ekström et al. (2007) and Eriksson et al. (2007). The character of the SMILES radiance data matches quite closely the radiative properties at $501 \mathrm{GHz}$, and, for example, the weighting functions found for this SMR band in Ekström et al. (2007) are approximately valid also for SMILES. As also shown in Ekström et al. (2007), the difference in brightness temperature between dry and wet (but still "clear-sky") conditions is $\sim 10 \mathrm{~K}$, while the dynamic range corresponding to cloud extinction is $\sim 100 \mathrm{~K}$ (Eriksson et al., 2007). Hence, it is suitable to first consider \% RHi as these retrievals are much more sensitive to instrumental or modelling problems.

\subsection{Relative humidity}

\subsubsection{Probability density functions}

A concise method to compare different data sets of retrieved data is to consider their probability density functions (PDFs), as done in Fig. 2. The a priori PDF for the SMILES and SMR retrievals is included (black line). The origin of these data is ECMWF; they were obtained through the ECMWFAUX CloudSat product (files downloaded 2008). Those old

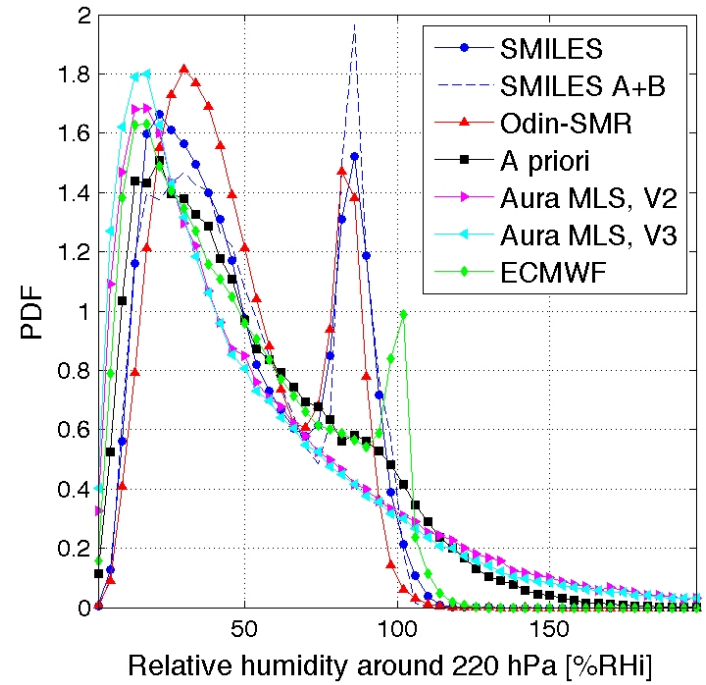

Figure 2. PDFs for a number of \%RHi data sets (see text for comments). The data cover slightly different layers around $220 \mathrm{hPa}$. The geographical area considered is latitudes between $20^{\circ} \mathrm{S}$ and $20^{\circ} \mathrm{N}$.

ECMWF data showed too little variability compared to the observations summarised in Ekström et al. (2008) and a random scaling factor was applied (Rydberg et al., 2009) to obtain a broader a priori PDF. More recent data from ECMWF are included for comparison (green line). These ECMWF (analysis) data are obtained with start August 2012 (IFS cycle 38 and later) and are sampled for each SMR measurement and averaged between 260 and $200 \mathrm{hPa}$. The new data give a significant PDF down to at least $5 \%$. In addition, the ECMWF system now allows supersaturation with respect to ice (Tompkins et al., 2007), which comes out as a peak in the PDF around $100 \%$ RHi. For the a priori PDF, the tail above $100 \%$ RHi is a result of the randomisation of the data.

The a priori PDF is significant as the SMR retrievals show a clear impact of a priori information, causing a wet bias for dry conditions and the opposite for wet conditions (Rydberg et al., 2009). That is, the a priori biases the retrievals towards the a priori mean. This effect is present also for SMILES, but is considerably smaller due to the more precise measurements. Considering this fact, it appears that the basic SMILES and SMR observations agree well. The two PDFs peak at 20 and $30 \% \mathrm{RHi}$, respectively. SMILES shows a slightly higher degree of supersaturation, but these differences are fully consistent with the higher a priori influence for SMR. This indicates that errors due to instrumental issues and uncertainties in spectroscopic parameters differ with less than $1 \mathrm{~K}$, expressed as an uncertainty in brightness temperature. However, this consistency estimate covers only differences between the instruments, and does not reflect the absolute accuracy.

Data for the $215 \mathrm{hPa}$ level from both MLS level 2 versions 2.2 and 3.3 are included. At this altitude there is little dif- 
ference between the two versions, but V3 is slightly drier. The MLS PDFs, as well as ECMWF, peak between 15 and $20 \%$ RHi. The first version of the SMR \%RHi retrievals did not use any a priori assumptions. In this case, PDFs peaking at $20 \%$ RHi were obtained (Ekström et al., 2008). This points towards SMILES having a wet bias at low \%RHi but a considerably smaller one than SMR. This wet bias is then partly caused by an under-representation of \%RHi below $20 \%$ in the a priori information (black line).

For both MLS versions, the PDF extends far above $120 \%$ RHi. There is no doubt that supersaturation with respect to ice exists in the upper troposphere (see e.g. Lamquin et al., 2012). However, to what extent mean relative humidity, averaged over large atmospheric volumes, matches strong supersaturation must still be treated as an open question. Only MLS version 3.3 is considered for the reminder of this paper.

The secondary peak in the SMILES and SMR PDFs around $85 \% \mathrm{RHi}$ corresponds to observations affected by cloud scattering, which is the case for less than $10 \%$ of the data points. With cloud scattering present, all direct measurement information for water vapour is lost and the inversion has to rely on a priori information. The outcome is the mean $\%$ RHi of the databases cases causing the same amount of scattering as observed. It is not probable that the complete measurement volume is fully covered by clouds, and the retrieved value becomes an average of \%RHi inside and outside cloudy air volumes. Hence, it is not totally certain that the PDF peak will occur exactly at $100 \% \mathrm{RHi}$, although the new ECMWF data give exactly such a peak. The difference of $15 \%$ RHi between the two PDF peaks can be taken as an estimate for the error of mean retrieved \% RHi in most cloudy regions, where Odin-SMR and SMILES most likely have a low bias.

Figure 2 includes data for SMILES A + B. As discussed in Sect. 3.4, this band combination contains less measurement information than the ones labelled together as "SMILES". Accordingly, a higher a priori influence could be expected and this is consistent with fewer retrievals around $30 \% \mathrm{RHi}$ and a more pronounced peak around $85 \%$ RHi. An alternative explanation could be a cold bias in brightness temperature in bands A and B and an opposing bias for band C, but a comparison between measured data and the a priori database gives no indications of such biases (Kasai et al., 2014).

\subsubsection{Geographical distributions and impact of ENSO}

Mean relative humidities are displayed in Fig. 3. The overall means of the data sets are given in Table 2. In the SMILES and SMR retrievals data are excluded only for technical reasons and the means can be considered as "all-weather" estimates. In the MLS processing, some data are excluded due to poor inversion convergence. Such cases mainly match strong scattering, and associated high humidity, a fact that contributes to the somewhat lower MLS mean.
Table 2. Mean value between $30^{\circ} \mathrm{S}$ and $30^{\circ} \mathrm{N}$ for considered retrieval data sets.

\begin{tabular}{lccc}
\hline $\begin{array}{l}\text { Retrieval } \\
\text { data set }\end{array}$ & $\begin{array}{c}\text { RHi } \\
{[\%]}\end{array}$ & $\begin{array}{c}\mathrm{pIWP}_{260 \mathrm{hPa}} \\
{\left[\mathrm{g} \mathrm{m}^{-2}\right]}\end{array}$ & $\begin{array}{c}\mathrm{pIWP}_{12.5 \mathrm{~km}} \\
{\left[\mathrm{~g} \mathrm{~m}^{-2}\right]}\end{array}$ \\
\hline SMILES & 46.9 & 9.2 & - \\
SMR & 45.0 & 9.7 & 2.8 \\
\hline MLS & 43.4 & - & - \\
CloudSat & - & 22.1 & 8.6 \\
MI2013 & - & - & 0.9 \\
\hline
\end{tabular}
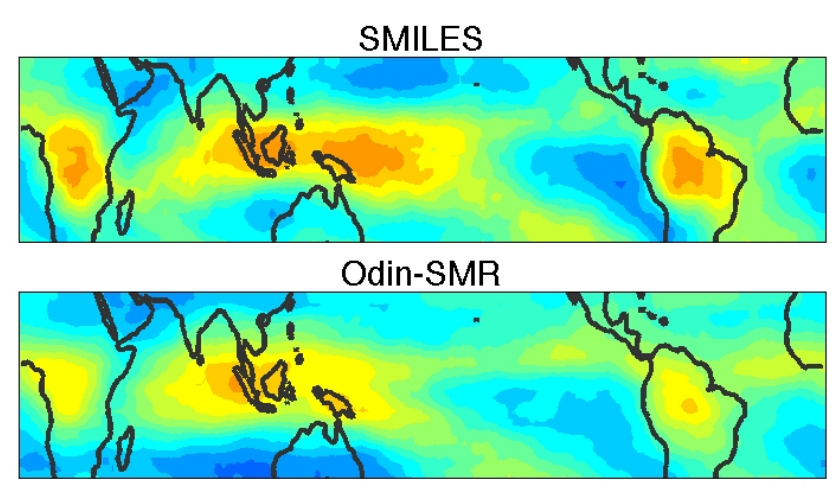

Aura MLS

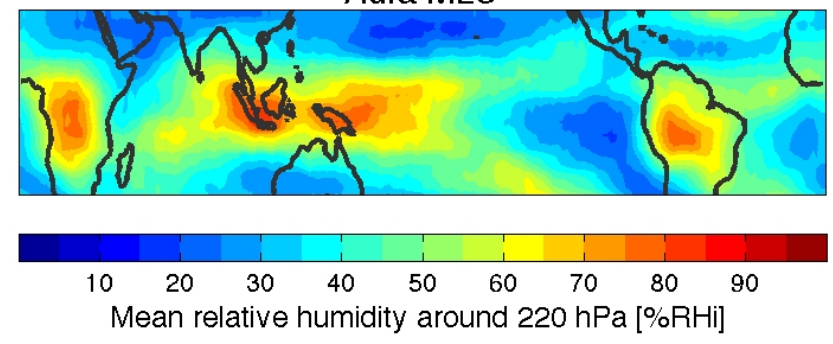

Figure 3. Average $\%$ RHi around $220 \mathrm{hPa}$ for some satellite data sets. The data represent a running average over $6^{\circ} / 12^{\circ}$ in latitude/longitude.

Regional averages differ more. Dry regions are drier and wet regions are wetter in the MLS averages than compared to SMILES and SMR. These features could be expected from the PDFs discussed above. The difference for most wet regions is on the order of $15 \% \mathrm{RHi}$, which matches the error estimate found in the previous section.

Besides this difference in contrast between wet and dry areas, the agreement between SMILES and MLS is high. SMR shows a different geographical distribution with the clearest deviation around the Equator in the western Pacific. The SMR data are averaged over 13 years but matched seasonally with the SMILES period. The difference in temporal coverage becomes especially important as the operational time of SMILES happens to coincide with a period of exceptionally high ENSO index. In fact, the complete SMILES period is characterised by high MEI (multivariate ENSO index; see http://www.esrl.noaa.gov/psd/enso/mei/ where also the MEI 


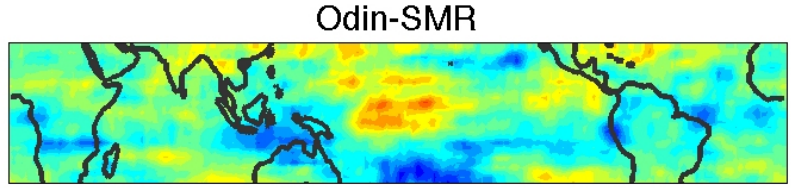

Aura MLS

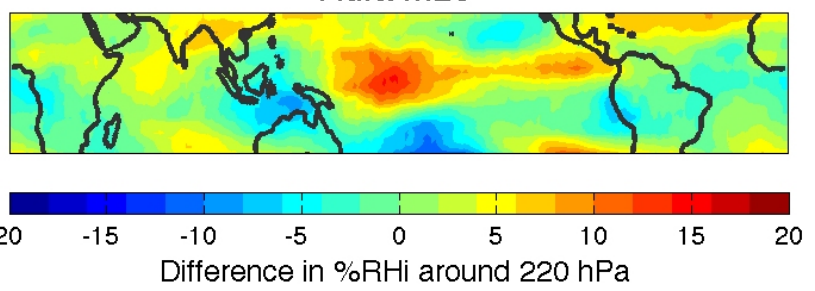

Figure 4. Difference in average $\%$ RHi around $220 \mathrm{hPa}$ between data corresponding to positive and negative MEI (positive minus negative). Data between 12 October and 21 April from complete SMR and MLS periods are included. The data represent a running average over $6^{\circ} / 12^{\circ}$ in latitude/longitude.

data used below were obtained), including the highest values since the 1998 El Niño.

The ENSO state is known to have a profound influence on the climate in parts of the tropics. This impact reaches also the upper troposphere, as illustrated by Fig. 4. The average humidities for all dates having positive and negative MEI have been determined and the difference is shown. The overall mean of the differences is +1.5 and $0.0 \% \mathrm{RHi}$ for MLS and SMR, respectively. Despite covering a longer time period, the SMR difference field has a more noisy appearance due to the considerably lower data volume. Some zonally aligned structures can also be discerned for SMR, such as a stripe of low values across Africa. This should be a consequence of the fact that Odin's scanning does not a have fixed latitude pattern and the sampling frequency of a region can vary between seasons and years.

The overall spatial patterns in Fig. 4 agree between SMR and MLS, with, for example, the highest positive correlation between MEI and mean humidity exactly where SMR deviates from SMILES and MLS in Fig. 3 (western equatorial Pacific). The maximum negative correlation is consistently placed east of Australia, and both instruments show also negative values over the Peruvian coast and between Indonesia and Australia.

However, there is a clear difference in how MLS and SMR capture the strongest changes in mean humidity. For example, MLS gives a larger increase in the western Pacific, while SMR shows higher negative values east of Australia. These differences should originate in different impact of a priori information and cloud interference, but also temporal drifts in the instruments could be involved. The latter issue is under investigation. A first, simple analysis based on overall tropical means revealed small trends for the two instruments, but of opposite signs.

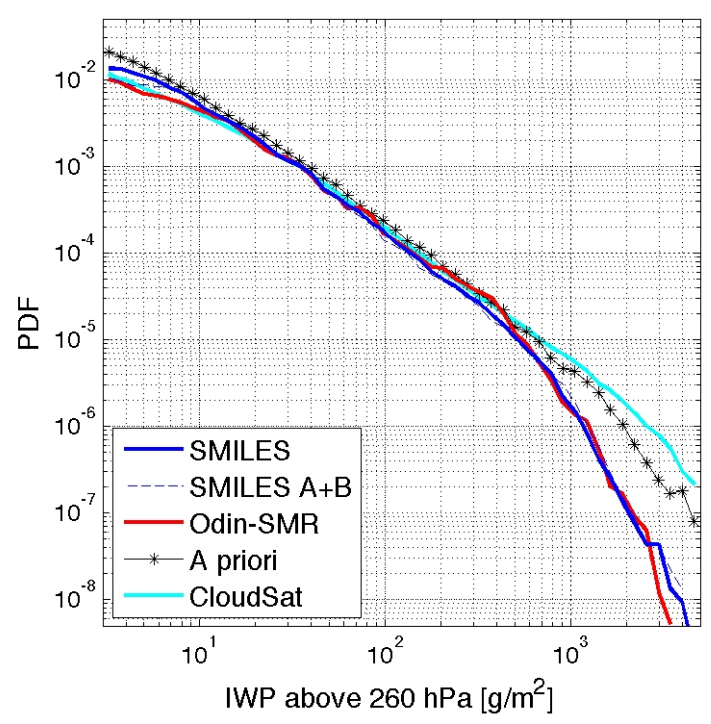

Figure 5. PDFs of pIWP $260 \mathrm{hPa}$ retrievals, i.e. estimated ice column above $260 \mathrm{hPa}$. The geographical area considered is latitudes between $30^{\circ} \mathrm{S}$ and $30^{\circ} \mathrm{N}$. The CloudSat data are averaged over $30 \mathrm{~km}$ to roughly match the footprint size of SMR and SMILES.

\subsection{Partial IWP}

\subsubsection{Probability density functions}

PDFs of pIWP $260 \mathrm{hPa}$ are shown in Fig. 5. All the data sets show a similar smooth decrease in PDF with increased $\mathrm{pIWP}_{260 \mathrm{hPa}}$. Between $\sim 15$ and $\sim 150 \mathrm{~g} \mathrm{~m}^{-2}$, all the PDFs agree closely. For lower $\mathrm{pIWP}_{260 \mathrm{hPa}}$, the a priori PDF is the highest, while for highest pIWP $_{260 \mathrm{hPa}}$, the CloudSat PDF is the highest. Similar PDF comparisons are found in e.g. Wu et al. $(2008,2009)$

The logarithmic scales in Fig. 5 make it difficult to judge how differences in the PDFs affect mean values. The mean value for one data set, $\bar{m}$, can be calculated as

$\bar{m}=\int_{0}^{\infty} p(m) m \mathrm{~d} m$,

where $m$ stands for pIWP, $p$ is the PDF and $\bar{m}$ is the average pIWP. The quantity $p(m) m$ is shown in Fig. 6 . The area under each curve in this figure corresponds to the overall $\bar{m}$ for each data set. This shows that the PDF differences above $\sim 200 \mathrm{~g} \mathrm{~m}^{-2}$ are the most relevant with respect to average mass.

Table 2 gives the overall mean of the retrieval data sets. The slightly higher mean for SMR compared to SMILES seems to originate in the 200 to $500 \mathrm{~g} \mathrm{~m}^{-2}$ range (Fig. 6), but to some extent is counteracted by SMILES's higher PDF below $10 \mathrm{~g} \mathrm{~m}^{-2}$ (Fig. 5).

The CloudSat mean is about a factor of 2.3 higher than SMILES and SMR. The higher CloudSat mean was partly 


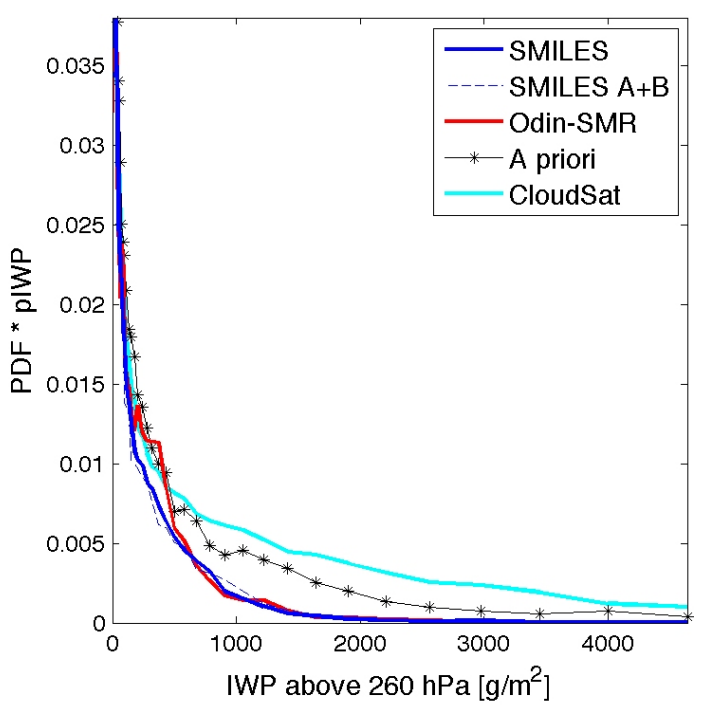

Figure 6. As Fig. 5, but PDFs weighted mean mass of each bin. The quantity displayed is part of Eq. (3).

expected due to different PSD assumptions. As mentioned in Sect. 3.2, the PSD of McFarquhar and Heymsfield (1997, below MH97) is applied to SMILES and SMR. In Eriksson et al. (2008), CloudSat retrievals based on MH97 were made and compared to the corresponding 2B-CWC-RO data. Besides IWC, Eriksson et al. (2008) considered a pIWP that should match pIWP $260 \mathrm{hPa}$ quite closely, and it was found that applying the MH97 PSD resulted in a mean factor of 1.5 lower than 2B-CWC-RO.

The remaining factor, also $\sim 1.5$, is partly caused by a bias towards the a priori mean similar to the one noted for \% RHi above. As discussed in Sect. 3.5.2 it is likely that there exists a saturation effect at high pIWP values, and this could be the main cause of the remaining part of the low bias. It has not been established to what extent the PSD assumptions contribute to the pronounced differences to CloudSat above $1000 \mathrm{~g} \mathrm{~m}^{-2}$ (Fig. 5).

\subsubsection{Geographical distributions and impact of ENSO}

Mean pIWP $260 \mathrm{hPa}$ as function of latitude and longitude is shown in Fig. 7. As noted above, SMILES and SMR exhibit lower overall means than CloudSat and a scaling factor is applied in order to use a common colour scale in the figure. Despite the scaling, SMILES is still lower than CloudSat. The difference is most pronounced in areas having high convective activity, where the highest pIWP values are found. Besides these aspects, there is a good agreement in the geographical distribution between CloudSat and SMILES. This fit with CloudSat is purely due to measurement information, as a single retrieval database is applied for all geographical positions (for both SMILES and Odin-SMR).

As for \% RHi, there are some deviations in the SMR field due to variations related to the ENSO. The impact of ENSO
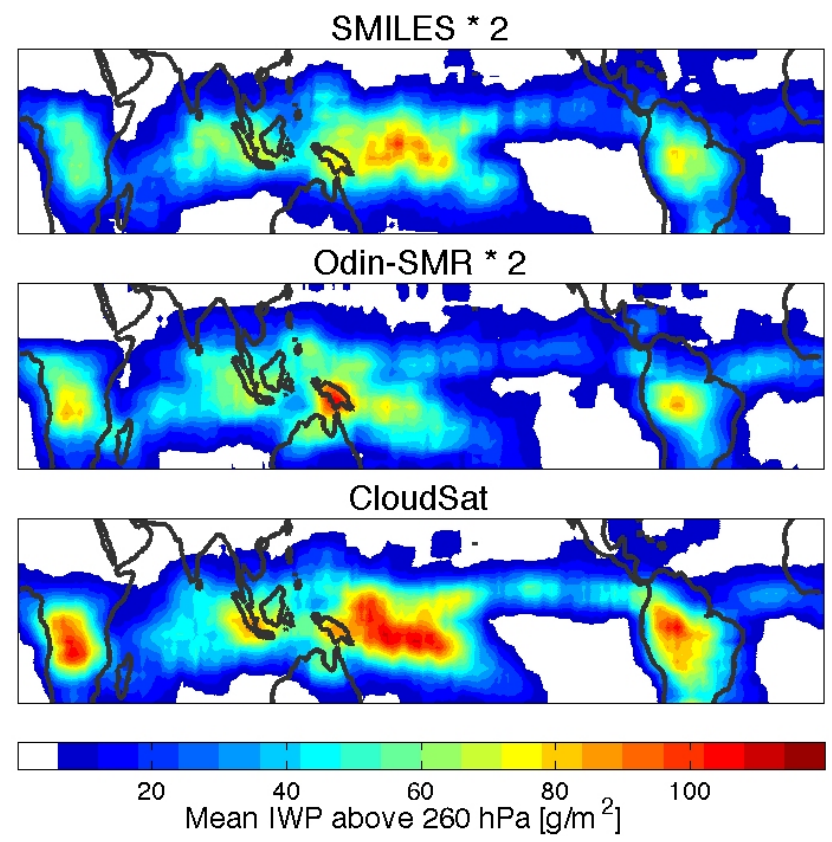

Figure 7. Average pIWP $260 \mathrm{hPa}$ for some satellite data sets. The data represent a running average over $8^{\circ} / 16^{\circ}$ in latitude/longitude. SMILES and SMR means are multiplied with a factor of 2 .

on $\mathrm{pIWP}_{260 \mathrm{hPa}}$ was derived for the complete tropical area and the regions defined in Fig. 8. The data were sorted according to MEI, and the mean for four ranges of MEI was determined (Fig. 9). The total tropical mean seems unaffected by MEI, i.e. indicating that the overall convective activity is not changed dramatically by the ENSO state. However, the region denoted as "Tropical Pacific" shows a clear positive correlation between pIWP $260 \mathrm{hPa}$ and MEI, fully consistent with the higher mean for SMILES in this region compared to the SMR one (Fig. 7).

The other regions also show some influence of MEI. The noticeable high pIWP $260 \mathrm{hPa}$ for "South America" and lowest MEI should correspond to a real change in pIWP $260 \mathrm{hPa}$, but smaller variations in Fig. 7 must be treated with some care. The main consideration is if the mean PSD and/or the diurnal phase of convection also vary with MEI, and the apparent change in pIWP $260 \mathrm{hPa}$ is in part, or fully, caused by such changes. Diurnal changes could possibly be analysed by combining different retrievals, but CloudSat's battery failure in 2011 complicates the situation as it changed the diurnal coverage of the data set. PSD influences are even harder to determine, as none of the existing satellite sensors is capable of actually determining the mass-relevant part of the PSD.

In summary, our judgement is that SMILES and SMR provide stable, and very similar, measurement information with respect to $\mathrm{pIWP}_{260 \mathrm{hPa}}$ : the differences noted above are mainly related to influences by ENSO and diurnal cycles (Sect. 4.3). However, significant limitations originate in the 


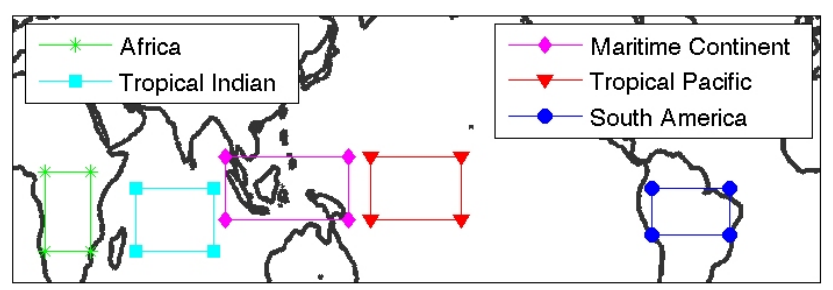

Figure 8. Definition of regions used in some of the later figures.

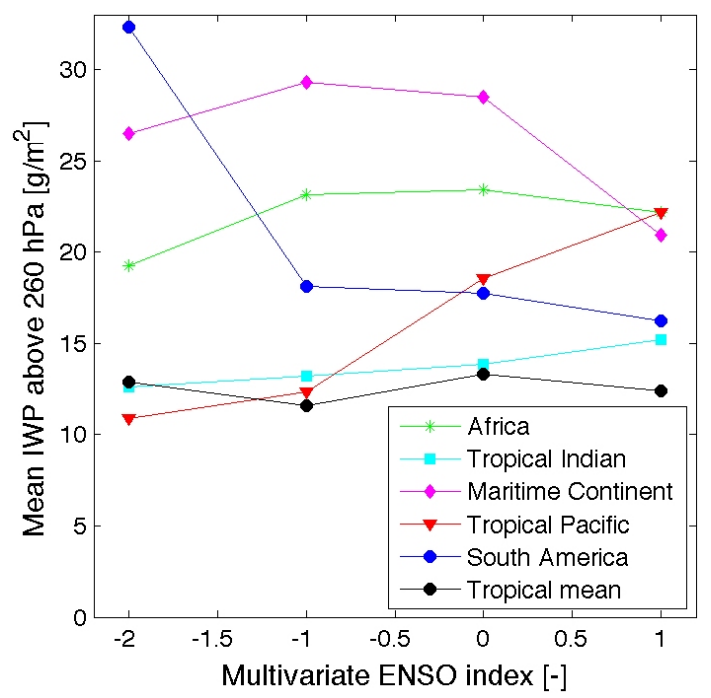

Figure 9. Total tropical and some regional means of SMR pIWP $260 \mathrm{hPa}$ as a function of modified ENSO index. The regions are defined in Fig. 8.

retrieval process, but these are common for the two instruments as a single methodology is used.

\subsubsection{Comparison to Millán et al. (2013)}

SMILES cloud ice retrievals were first provided by Millán et al. (2013, below MI2013). They based the retrievals on a merge of Calipso and CloudSat IWC data and considered a higher range of tangent altitudes, where measurements at higher altitudes were mapped to IWC. That part of the data set is not considered here. For "low tangent" altitudes the retrieval product is a partial ice water path, as in this study, but MI2013 set the limit at $12.5 \mathrm{~km}\left(\mathrm{pIWP}_{12.5 \mathrm{~km}}\right)$, instead of $260 \mathrm{hPa}(\mathrm{pIWP} 260 \mathrm{hPa}$, matching $\approx 10.5 \mathrm{~km})$.

We did not see the point of creating a second SMILES

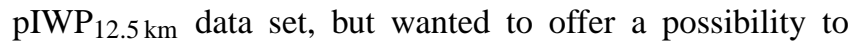
combine the MI2013 data with SMR retrievals. Hence, pIWP $_{12.5 \mathrm{~km}}$ was added to the SMR state vector and these retrievals were added to the publicly available data files. Relevant PDFs are found in Fig. 10. The SMR PDF roughly follows the CloudSat one, but the deviation is larger here. The CloudSat mean pIWP $12.5 \mathrm{~km}$ is a factor 3.1 higher than SMR (Table 2), compared to 2.3 for $\mathrm{pIWP}_{260 \mathrm{hPa}}$. An increase

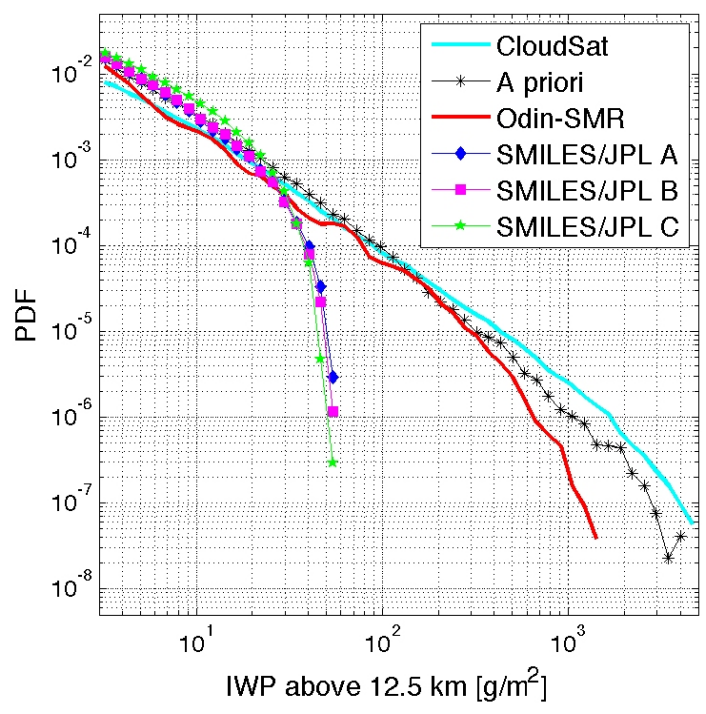

Figure 10. PDFs of $\mathrm{pIWP}_{12.5 \mathrm{~km}}$ data. Data from Millán et al. (2013) are denoted as "SMILES/JPL". Otherwise as in Fig. 5.

in this factor is expected as the impact of differences in the PSD assumptions gets more pronounced with height (Eriksson et al., 2008).

The differences in shape of the MI2013 and SMR PDFs are not caused by PSD issues, as MH97 is used in both cases. The mean of MI2013 is $0.8 / 0.8 / 1.0 \mathrm{~g} \mathrm{~m}^{-2}$ for bands A / B / C, respectively, i.e. a factor of $\sim 10$ below the CloudSat mean. The lower MI2013 means are clearly associated with a lack of retrievals having values above $\sim 60 \mathrm{~g} \mathrm{~m}^{-2}$. Several factors could be involved in explaining the lower MI2013 means. "Beam filling" is one such factor (Sect. 3.2). A particular strength of the methodology of Rydberg et al. (2009) is the detailed handling of beam filling, while MI2013 handles this aspect in less detail. Further, in MI2013 the impact on the measurements for a given pIWP $_{12.5 \mathrm{~km}}$ is overestimated as the forward model applied (Wu et al., 2008) makes use of a single scattering assumption. In addition, the relationship between $T_{\mathrm{b}}$ and pIWP is assumed to be linear, while for higher ice masses the relationship is rather linear with respect to $\log$ (pIWP); see e.g. Eriksson et al. (2007, Fig. 5). The combined effect appears to be a strong underestimation at higher $\mathrm{pIWP}_{12.5 \mathrm{~km}}$.

\subsection{Diurnal variations}

The orbit of ISS gives SMILES among limb sounders a unique opportunity to study diurnal effects. This feature is valid for all the quantities measured by SMILES (e.g. Kreyling et al., 2013). For a particular region, there is not an instantaneous complete coverage in local time and only seasonal mean variations can be derived. Here the data from the complete SMILES period are combined. 


\subsubsection{Relative humidity}

Results for relative humidity are found in Fig. 11. The regions considered (Fig. 8) are taken from Eriksson et al. (2010, below ER2010), to allow comparison with that study. To compensate for ENSO influences and the fact that ER2010 considered a slightly higher layer than the one selected for the SMILES retrievals, the mean of the ER2010 results is adjusted to match the ones derived for SMILES. Hence, the comparison ignores mean levels, and focuses on diurnal phases and amplitudes. As reference, the long-term MLS and SMR means for the season are included, indicating the sampling achieved by sun-synchronous orbiting sensors. The estimates in ER2010 were based on MLS and SMR, but then for a shorter and common time period. In addition, SMR mean values were adjusted to compensate for a priori influences, following Rydberg et al. (2009).

The results in Fig. 11 vary between the regions. The best agreement between the data sets is found for "Tropical Indian". This is probably also the region with the lowest degree of observations with significant cloud scattering (Eriksson et al., 2007, Fig. 9) and this region shows low influence of MEI (Figs. 4 and 9). These aspects are more important for the other regions considered, and deviations between the data sets can be observed.

ER2010 found the strongest diurnal cycles over the two land regions $(\approx \pm 7 \% \mathrm{RHi})$, and the updated SMR and MLS averages indicate the same. Taking into account that SMR means have a dry bias for wet regions like these, the land diurnal cycle stands out mainly through a higher mean of the 01:30 MLS data point. SMILES confirms the ER2010 results for "Africa", while for an unknown reason basically no cycle at all is found for "South America".

The SMILES and ER2010 diurnal amplitudes agree well also above the "Maritime Continent" $(\approx \pm 3 \% \mathrm{RHi})$. The SMILES and ER2010 max points are also quite close, 02:00 and 04:30 respectively, but the SMILES diurnal variation does not show a distinct single diurnal maximum. For "Tropical Pacific" there is an about $15 \%$ RHi difference in diurnal mean value between SMILES and the long-term SMR and MLS averages, as expected from Fig. 4. ER2010 found a $\approx$ $\pm 2 \%$ RHi diurnal amplitude and SMILES indicates a slightly higher value. SMILES gives a minimum around 09:00 and a basically constant, higher, value between 13:00 and 05:00 the next day. This kind of diurnal variation could not be captured by ER2010, which could estimate only the first harmonic of the diurnal cycle. In fact, the minimum around 09:00 is largely missed by MLS and SMR, despite the two instruments together giving a very even coverage of the range of local times.

\subsubsection{Partial IWP, observations}

Diurnal variations of $\mathrm{pIWP}_{260 \mathrm{hPa}}$ as observed by SMILES are illustrated in Fig. 12. These results are also displayed in

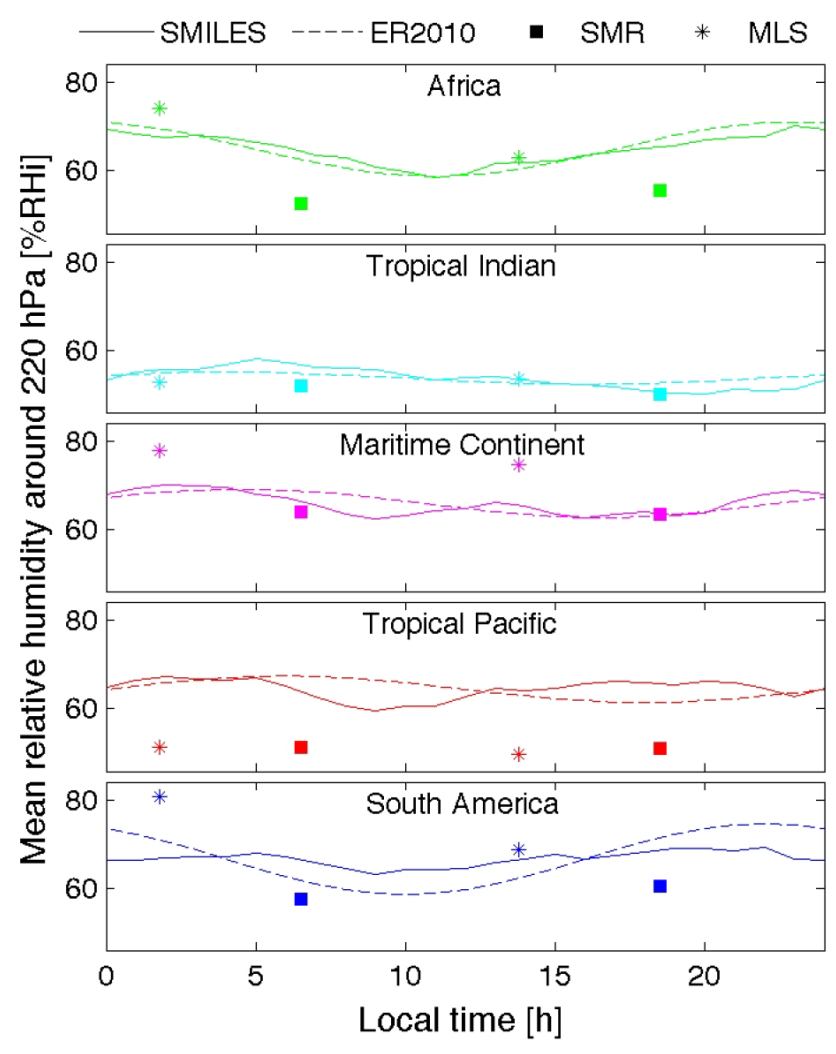

Figure 11. Diurnal variations of $\%$ RHi around $220 \mathrm{hPa}$. Solid lines are $6 \mathrm{~h}$ running means of the SMILES data. Dashed lines are given the same mean as the corresponding solid line, but diurnal phase and amplitude are taken from Eriksson et al. (2010). For MLS and SMR, data between 12 October 2009 and 21 April 2010 from complete mission periods are included.

Fig. 13 as the relative deviation to the mean of each region in order to facilitate comparison with ER2010 and MI2013.

ER2010 did not consider any pIWP, only IWC for a $\approx$ $4 \mathrm{~km}$ thick layer around $190 \mathrm{hPa}$. In Fig. 13 it is assumed that the relative amplitudes and phases for IWC in this layer are valid approximately also for $\mathrm{pIWP}_{260 \mathrm{hPa}}$. The most pronounced cycles in absolute cloud ice mass were found over land. SMILES confirms this for both "Africa" and "South America" (Fig. 12), and also reveals that the rise from low values during morning to the peak around 18:00 occurs more quickly (Fig. 13) than implied by the single harmonic fit used by ER2010. According to SMILES, the evening peak in pIWP $260 \mathrm{hPa}$ is broader (in time) over "Africa" than over "South America", causing the fit of ER2010 to be acceptable for "Africa" but giving an underestimation of the diurnal amplitude for "South America". The SMR data points fit with the discussion above (Fig. 12), indicating that the SMILES results should be of general validity and not only represent the particular observation period of SMILES.

Both SMILES and ER2010 find that the "Tropical Indian" region has its peak pIWP around sunrise, and that the diurnal 


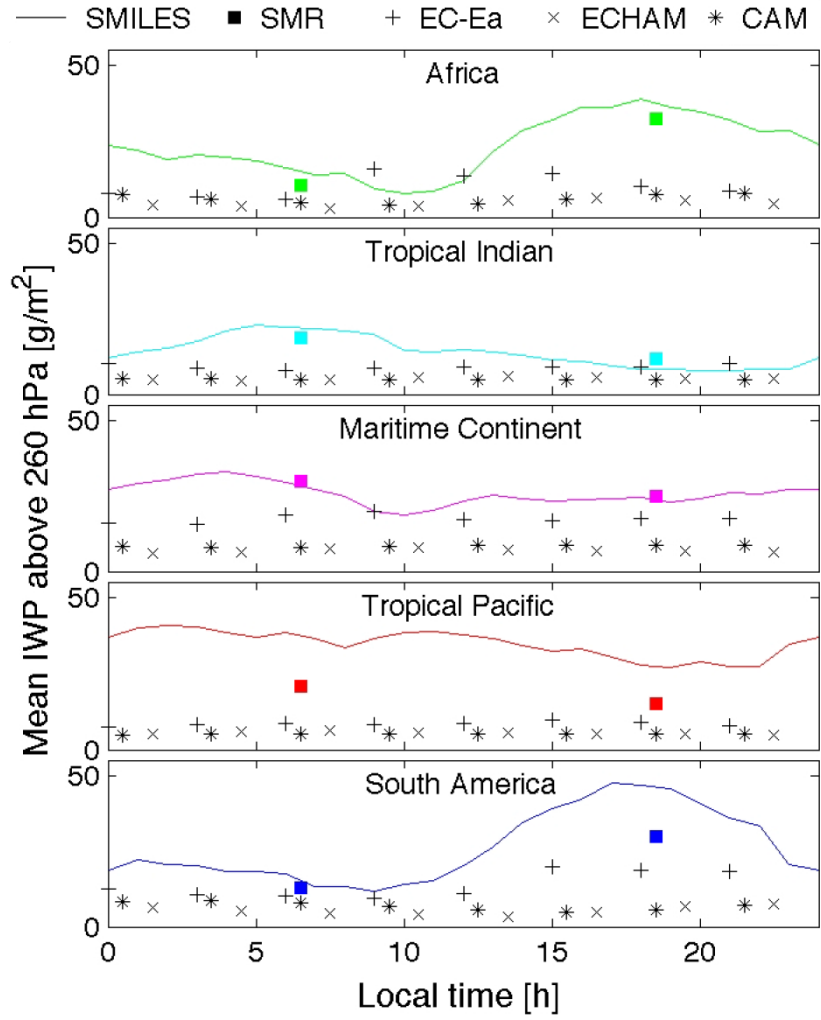

Figure 12. Diurnal variations of $\mathrm{pIWP}_{260 \mathrm{hPa}}$. Solid lines are $6 \mathrm{~h}$ running means of the SMILES data. For SMR, data between 12 October 2009 and 21 April 2010 from the complete mission period are included. Black markers are global climate model results, only covering "cloud ice", where * is CAM5, $\times$ is ECHAM6 and + is EC-Earth3 (all uncoupled, 2007-2008).

amplitude is high in relative terms, $\approx \pm 50 \%$. For "Tropical Pacific", there is a rough match in the size of the amplitude $(\approx \pm 25 \%)$, but there is a disagreement around the peak time. As for $\% \mathrm{RHi}$, a diurnal variation for SMILES stands out primarily due to a period over lower values, around 21:00 for pIWP $260 \mathrm{hPa}$. The "Maritime Continent" shows a limited diurnal variation, $\approx \pm 10 \%$. This is probably explained by the fact that the region covers both land and ocean areas, and these more large-scale means are created by a combination of local cycles having different diurnal phases.

It will be remembered that SMILES did not have instantaneous diurnal coverage and different parts of the diurnal cycles are sampled during different months. This means that seasonal variability (such as movement of the ITCZ) during the SMILES period has an impact on the diurnal cycles derived. The same is true for changes in the ENSO state during the period. Such aspects could have contributed to the less smooth cycles for "Tropical Pacific" and "Maritime Continent".

Also MI2013 (Millán et al., 2013) considered regional mean diurnal cycles of pIWP. They reported the relative deviation from the local mean $\mathrm{pIWP}_{12.5 \mathrm{~km}}$. The selection of

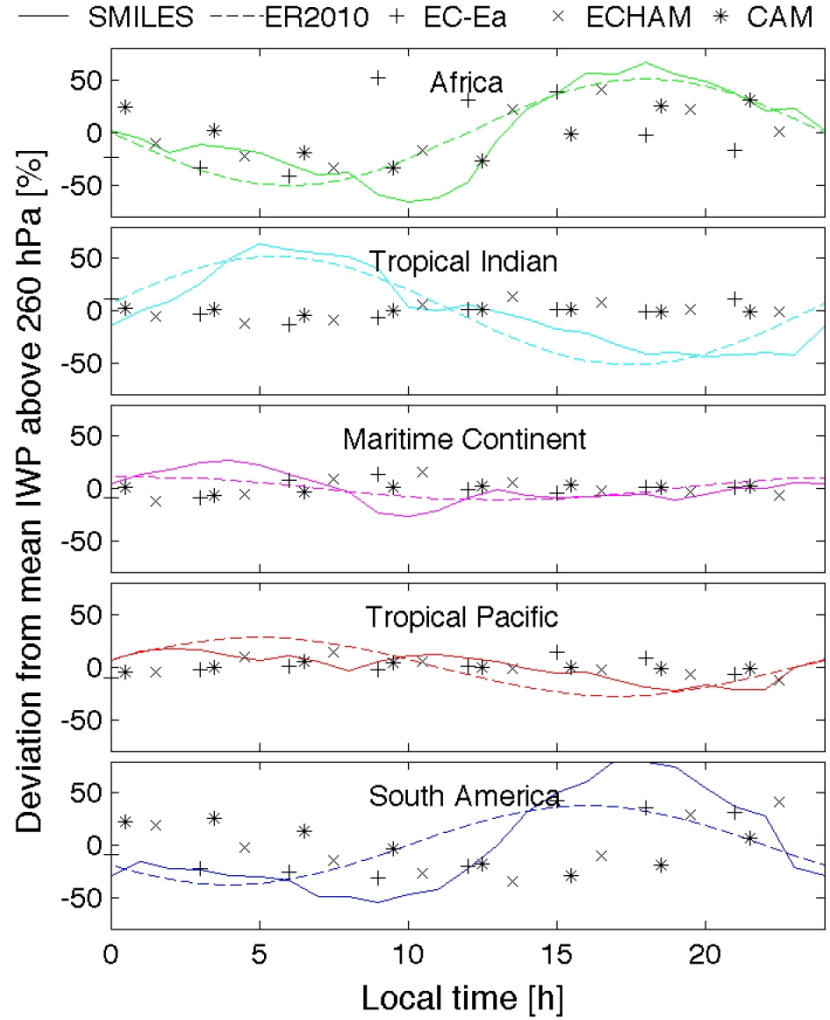

Figure 13. Diurnal variations of $\mathrm{pIWP}_{260 \mathrm{hPa}}$, expressed as the relative deviation from the local mean of each data set. Solid lines are $6 \mathrm{~h}$ running means of the SMILES data. Dashed lines represent the relative variation in ice water content derived in Eriksson et al. (2010). Black markers are global climate model results, only covering "cloud ice", where * is CAM5, $\times$ is ECHAM6 and + is ECEarth3 (all uncoupled, 2007-2008).

regions is similar to the one here, but in MI2013 the cycles have hourly time resolution. MI2013 found a general agreement with earlier studies, including ER2010. Hence, there is also a high similarity between the diurnal cycles based on SMILES data in Fig. 13 and the ones found in MI2013. However, there is one noticeable deviation: the amplitude for "Tropical Indian" is considerable smaller in MI2013, about $\pm 25 \%$ compared to the $\pm 50 \%$ found in this study.

The fit between MI2013 and Fig. 13 is particularly good for the land regions, including the more narrow afternoon peak over "South America", compared to "Africa", as discussed above. This feature stands out better in the analysis of MI2013, where less time averaging is applied. This indicates that convective activity lasts longer, or the diurnal cycle is less regular, over "Africa". Potentially, different ice particle fall speeds could also be involved. However, SMILES covered only 6 months and any discussion of such differences based on these results alone becomes highly speculative. 


\subsubsection{Partial IWP, model results}

Unfortunately, it is not a simple task to compare observational and model cloud ice mass data. Satellite sensors have direct sensitivity only to a limited range of ice particle sizes. The satellite retrievals presented here aim at giving the complete ice mass, but the sensors (including CloudSat) have in fact little sensitivity to ice particles smaller than $100 \mu \mathrm{m}$ (Eriksson et al., 2008). However, more problematic is that climate models normally include only "cloud ice" (or "nonprecipitating" ice) in their IWC output. This model output is below denoted as CI (cloud ice). Extraction of "precipitating" ice (or "snow") requires, in general, special runs, where internal diagnostic variables are stored. In addition, the conversion of "snow fluxes" to IWC can involve assumptions of ice particle fall speeds (for a more detailed discussion, see e.g. Waliser et al., 2009 and Johnston et al., 2012).

ER2010 included a comparison to data from the CAM3, ECHAM5 and EC-Earth2 global climate models. The conclusion was that these models underestimated the cloud ice mass. As a consequence, the generated diurnal variation in absolute pIWP became also too small, but there were also problems in some of the models regarding the phase of the diurnal cycles. Adding "precipitating" ice to the models' CI gave some improvement for the mean ice mass (particularly for ECHAM5), but had marginal impact on relative amplitude and diurnal phase.

Figures 12 and 13 include data from later versions of the same models. These data are taken from Johnston et al. (2014), where also details around the model versions are found. The model data displayed include only the CI part. Hence, a direct comparison to the satellite data is not possible, and mainly changes compared to ER2010 are discussed. The model data cover the parts of 2007-2008 that match seasonally with SMILES.

In ER2010, EC-Earth2 had the highest CI mean value for all the five regions, and this is still the case. As a consequence, EC-Earth3 is the only model showing an absolute diurnal variation in $\mathrm{pIWP}_{260 \mathrm{hPa}}$ above $4 \mathrm{~g} \mathrm{~m}^{-2}$. The relative diurnal amplitudes are more similar between the models. These amplitudes agree roughly with the observations, except for "Tropical Indian" where all the models exhibit a very weak diurnal cycle. In ER2010, CAM3 and EC-Earth2 showed a relative amplitude that exceeded that observed for the land regions, but this is not the case in Fig. 13 for the newer model versions.

The diurnal timing of convection is a known problematic area for climate models (e.g. Johnston et al., 2014), and this deficiency impacts negatively on the diurnal cycles of concern here. Some differences to ER2010 can be noted. In that study, ECHAM5 stood out as the best model with respect to diurnal timing. In fact, ECHAM5 was inside the observational uncertainty range for all five regions, but in Fig. 13 ECHAM6 lags somewhat in time for both "South America" and "Tropical Indian". This is a change in ECHAM6 at least for the CI part. In ER2010 maxima in ECHAM5's CI and IWC were close throughout in local time, but that could have changed and there could still be an agreement with the observations for total model IWC.

In ER2010, CAM3 showed a very similar diurnal phase for all regions (between 20:00 and 24:00). There is now a higher variability for CAM5 between the regions, but the fit with the observations is still limited. EC-Earth2 had a too early phase in ER2010 for both land regions (around 11:00). This is still the case for "Africa", where the diurnal cycle shows a steplike feature around 09:00. On the other hand, an improvement can be discerned in EC-Earth3 for "South America", where the agreement with the observations in Fig. 13 now is better.

As only CI is included, the models should be low when compared to observational estimates of (total) ice mass, as in Fig. 12. However, ER2010 found that adding the missing precipitating part did not bring the model mean IWC up to the observed values. This issue was analysed further for EC-Earth2 in Johnston et al. (2012), and it was found that CI dominates in this model above $200 \mathrm{hPa}$ (but the situation is reversed below $300 \mathrm{hPa}$ ). In addition, the models are here compared to SMILES and SMR estimates that have a considerably low bias compared to CloudSat retrievals. Accordingly, it is highly likely that the models still underestimate the total ice mass at altitudes above $250 \mathrm{hPa}$.

\section{Conclusions}

A new data set of SMILES retrievals is introduced. The data set contains estimates of the mean relative humidity between 260 and $200 \mathrm{hPa}$ and the (partial, vertical) ice water path above $260 \mathrm{hPa}\left(\mathrm{pIWP}_{260 \mathrm{hPa}}\right)$. Humidities are also available as volume mixing ratios (VMRs), but those retrievals are not considered in this paper as they are less accurate and the relative humidity product is recommended for scientific use. For both SMILES and SMR, the VMR retrievals are found on the same website as the standard data (see Sects. 2.1 and 2.2).

A retrieval methodology (Rydberg et al., 2009) developed for the similar Odin-SMR instrument is used. The approach is applied in a basically identical manner for the two instruments. In this paper, the SMR retrievals are extended to cover 2002-2013, and VMR and the SMILES data products are added as retrieval quantities: the latter to facilitate comparisons and combining the SMILES and SMR data. Both data sets are publicly available.

The SMILES receiver had an excellent noise performance, and this results in a lower impact of a priori assumption on the relative humidities retrievals. Besides this, it is judged that SMR and SMILES provide highly matching data. Measurements are filtered only according to possible technical problems (incorrect calibration etc.). For each measurement, both humidity and ice mass are retrieved, but in the case of significant scattering the humidity reported reflects only a 
priori information. Accordingly, the retrievals can be classified as "all-weather" and averaged values can be directly compared to means derived for, for example, an atmospheric model, which is in contrast to many other satellite retrievals.

There is a good agreement between these humidity retrievals and Aura MLS with respect to overall mean and geographical distribution. However, the SMILES and SMR retrievals show lower fractions of very low and high humidities. This lower spread in retrieved \%RHi is only partly explained by a priori influences, and other causes for the deviations at most dry and wet conditions should be considered for all involved instruments.

The consistency between the retrievals presented and CloudSat is good regarding the geographical distribution of cloud ice mass, but the SMILES and SMR retrievals result in lower mean values. It is clear that SMILES and SMR have a low bias due to a priori influences and saturation effects, particularly for high pIWP. On the other hand, the difference to CloudSat also originates partly in PSD assumptions and on this point it is likely that all involved retrievals have systematic errors. An even stronger low bias, compared to CloudSat, was found for the SMILES retrievals presented by Millán et al. (2013). The PSD of McFarquhar and Heymsfield (1997) was selected both for this study and by Millán et al. (2013). Recent results in Wu et al. (2014) indicate that this PSD is less realistic than what is assumed in the CloudSat retrievals, at least for altitudes around $15 \mathrm{~km}$.

The main drawback of the retrievals is the limited size of the data sets. The spatial coverage is restricted to the tropical $\left(30^{\circ} \mathrm{S}\right.$ to $\left.30^{\circ} \mathrm{N}\right)$ upper troposphere. SMILES provided relatively dense measurements (for a limb sounder), but only for slightly more than 6 months. The sampling frequency of SMR is low, but the total time coverage has now passed 12 years. However, both satellites complement other, more established measurements in regard to local time sampling. The measurements of SMILES drifted in local time, and full sampling of seasonally averaged diurnal cycles can be achieved. This fact was used to improve on results from Eriksson et al. (2010), where SMR was combined with Aura MLS and CloudSat to obtain a rough sampling of the diurnal cycle of humidity and ice mass for a number of regions. The main results from Eriksson et al. (2010) were confirmed; amplitude and phase of the diurnal cycles agree in general between the two studies. The main exception is that SMILES shows no diurnal variation for relative humidity over the "South America" region.

In addition, SMILES shows that the diurnal cycles are more complex than the single harmonics assumed by Eriksson et al. (2010), implying that observations from sensors not locked into sun-synchronous orbits are required for detailed investigations of diurnal cycles. Geostationary satellites are in principle ideal for diurnal studies, but these platforms still lack the microwave sensors needed to penetrate the dense cloud decks covering the regions where the most pronounced diurnal cycles are found.
Model data on "cloud ice" from CAM5, ECHAM6 and EC-Earth3 were considered, and some progress compared to Eriksson et al. (2010) was noted. The improvements were found for diurnal timing and relative amplitudes, while the models are judged to still exhibit too low total ice mass. However, clear conclusions on these issues are still very difficult to reach due to limitations on both model and measurement sides. The long-time coverage of SMR was used to exemplify the impact of the ENSO state on water in the tropical upper troposphere. Clear signatures were found for both humidity and cloud ice mass, with the highest increase during El Niño conditions in the western tropical Pacific for both quantities. These initial results on diurnal cycles and correlation with ENSO were mainly included to demonstrate possible applications of the SMILES and SMR data sets, and more detailed analyses and comparisons with model data will follow.

A new version of the retrieval database will be considered. The main points for improvements are then: revise the PSD assumptions, to use single scattering properties for more realistic ice particle shape(s), include a higher fraction of cases having a humidity below $20 \% \mathrm{RHi}$, and revise the assumption on humidity in and around cloudy regions.

Acknowledgements. These cloud ice mass retrievals were made possible by the development of ARTS and the community around this forward model is acknowledged for its contributions. The work by Patrick Eriksson was made possible by a grant of the Swedish National Space Board. CAM5 and ECHAM6 model data were kindly provided by Andrew Gettelman (UCAR) and Petri Räisänen (FMI), respectively.

Edited by: F. Khosrawi

\section{References}

Austin, R. T., Heymsfield, A. J., and Stephens, G. L.: Retrieval of ice cloud microphysical parameters using the CloudSat millimeter-wave radar and temperature, J. Geophys. Res., 114, D00A23, doi:10.1029/2008JD010049, 2009.

Baron, P., Urban, J., Sagawa, H., Möller, J., Murtagh, D. P., Mendrok, J., Dupuy, E., Sato, T. O., Ochiai, S., Suzuki, K., Manabe, T., Nishibori, T., Kikuchi, K., Sato, R., Takayanagi, M., Murayama, Y., Shiotani, M., and Kasai, Y.: The Level 2 research product algorithms for the Superconducting Submillimeter-Wave Limb-Emission Sounder (SMILES), Atmos. Meas. Tech., 4, 2105-2124, doi:10.5194/amt-4-2105-2011, 2011.

Buehler, S. A., Jiménez, C., Evans, K. F., Eriksson, P., Rydberg, B., Heymsfield, A. J., Stubenrauch, C., Lohmann, U., Emde, C., John, V. O., Sreerekha, T. R., and Davis, C. P.: A concept for a satellite mission to measure cloud ice water path and ice particle size, Q. J. Roy. Meteorol. Soc., 133, 109-128, doi:10.1002/qj.143, 2007.

Buehler, S. A., Eriksson, P., and Lemke, O.: Absorption lookup tables in the radiative transfer model ARTS, J. Quant. Spectrosc. Ra. Transfer, 112, 1559-1567, doi:10.1016/j.jqsrt.2011.03.008, 2011. 
D’Addio, S., Kangas, V., Klein, U., Loiselet, M., and Mason, G.: The microwave radiometers on-board MetOp second generation satellites, in: Metrology for Aerospace (MetroAeroSpace), 2014 IEEE, pp. 599-604, Benevento, Italy, doi:10.1109/MetroAeroSpace.2014.6865995, 2014.

Davis, C., Emde, C., and Harwood, R.: A 3D polarized reversed Monte Carlo radiative transfer model for $\mathrm{mm}$ and sub-mm passive remote sensing in cloudy atmospheres, IEEE T. Geosci. Remote, 43, 1096-1101, doi:10.1109/TGRS.2004.837505, 2005.

Davis, C. P., Evans, K. F., Buehler, S. A., Wu, D. L., and Pumphrey, H. C.: 3-D polarised simulations of space-borne passive $\mathrm{mm} / \mathrm{sub}-$ mm midlatitude cirrus observations: a case study, Atmos. Chem. Phys., 7, 4149-4158, doi:10.5194/acp-7-4149-2007, 2007.

Ekström, M. and Eriksson, P.: Altitude resolved ice-fraction in the uppermost tropical troposphere, Geophys. Res. Lett., 35, L13822, doi:10.1029/2008GL034305, 2008.

Ekström, M., Eriksson, P., Rydberg, B., and Murtagh, D. P.: First Odin sub-mm retrievals in the tropical upper troposphere: humidity and cloud ice signals, Atmos. Chem. Phys., 7, 459-469, doi:10.5194/acp-7-459-2007, 2007.

Ekström, M., Eriksson, P., Read, W. G., Milz, M., and Murtagh, D. P.: Comparison of satellite limb-sounding humidity climatologies of the uppermost tropical troposphere, Atmos. Chem. Phys., 8, 309-320, doi:10.5194/acp-8-309-2008, 2008.

Eriksson, P., Ekström, M., Rydberg, B., and Murtagh, D. P.: First Odin sub-mm retrievals in the tropical upper troposphere: ice cloud properties, Atmos. Chem. Phys., 7, 471-483, doi:10.5194/acp-7-471-2007, 2007.

Eriksson, P., Ekström, M., Rydberg, B., Wu, D. L., Austin, R. T., and Murtagh, D. P.: Comparison between early Odin-SMR, Aura MLS and CloudSat retrievals of cloud ice mass in the upper tropical troposphere, Atmos. Chem. Phys., 8, 1937-1948, doi:10.5194/acp-8-1937-2008, 2008.

Eriksson, P., Rydberg, B., Johnston, M., Murtagh, D. P., Struthers, H., Ferrachat, S., and Lohmann, U.: Diurnal variations of humidity and ice water content in the tropical upper troposphere, Atmos. Chem. Phys., 10, 11519-11533, doi:10.5194/acp-1011519-2010, 2010.

Eriksson, P., Buehler, S. A., Davis, C. P., Emde, C., and Lemke, O.: ARTS, the atmospheric radiative transfer simulator, Version 2, J. Quant. Spectrosc. Ra. Transfer, 112, 1551-1558, doi:10.1016/j.jqsrt.2011.03.001, 2011a.

Eriksson, P., Rydberg, B., and Buehler, S. A.: On cloud ice induced absorption and polarisation effects in microwave limb sounding, Atmos. Meas. Tech., 4, 1305-1318, doi:10.5194/amt-4-13052011, 2011b.

Evans, K. F. and Stephens, G. L.: Microwave radiative transfer through clouds composed of realistically shaped ice crystals. Part I: Single scattering properties, J. Atmos. Sci., 52, 2041-2057, 1995.

Evans, K. F., Turk, J., Wong, T., and Stephens, G. L.: A Bayesian approach to microwave precipitation profile retrieval, J. Appl. Meteorol., 34, 260-279, 1995.

Evans, K. F., Evans, A. H., Nolt, I. G., and Marshall, B. T.: The prospect for remote sensing of cirrus clouds with a submillimeter-wave spectrometer, J. Appl. Meteorol., 38, 514-525, 1999.

Hartmann, D.: Radiative effects of clouds on Earth's climate, Int. Geophysics Series, 54, 151-151, 1993.
Johnston, M., Eriksson, P., Eliasson, S., Jones, C., Forbes, R., and Murtagh, D.: The representation of tropical upper tropospheric water in EC Earth V2, Clim. Dynam., 39, 2713-2731, doi:10.1007/s00382-012-1511-0, 2012.

Johnston, M. S., Eliasson, S., Eriksson, P., Forbes, R. M., Gettelman, A., Räisänen, P., and Zelinka, M. D.: Diagnosing the average spatio-temporal impact of convective systems - Part 2: A model intercomparison using satellite data, Atmos. Chem. Phys., 14, 8701-8721, doi:10.5194/acp-14-8701-2014, 2014.

Kasai, Y., Rydberg, B., and Möller, M.: Retrieval theoretical basis of NICT/SMILES level-2 products: upper tropospheric cloud ice mass and water vapor, Tech. rep., National Institute of Information and Communications Technology, Tokyo, Japan, 2014.

Kikuchi, K., Nishibori, T., Ochiai, S., Ozeki, H., Irimajiri, Y., Kasai, Y., Koike, M., Manabe, T., Mizukoshi, K., Murayama, Y., Nagahama, T., Sano, T., Sato, R., Seta, M., Takahashi, C., Takayanagi, M., Masuko, H., Inatani, J., Suzuki, M., and Shiotani, M.: Overview and early results of the Superconducting Submillimeter-Wave Limb-Emission Sounder (SMILES), J. Geophys. Res., 115, D23306, doi:10.1029/2010JD014379, 2010.

Kreyling, D., Sagawa, H., Wohltmann, I., Lehmann, R., and Kasai, Y.: SMILES zonal and diurnal variation climatology of stratospheric and mesospheric trace gases: $\mathrm{O}_{3}, \mathrm{HCl}, \mathrm{HNO}_{3}, \mathrm{ClO}, \mathrm{BrO}$, $\mathrm{HOCl}, \mathrm{HO}_{2}$, and temperature, J. Geophys. Res., 118, 11-888, 2013.

Kummerow, C., Olson, W. S., and Giglio, L.: A simplified scheme for obtaining precipitation and vertical hydrometeor profiles from passive microwave sensors, IEEE T. Geosci. Remote, 34, 1213-1232, 1996.

Lamquin, N., Stubenrauch, C. J., Gierens, K., Burkhardt, U., and Smit, H.: A global climatology of upper-tropospheric ice supersaturation occurrence inferred from the Atmospheric Infrared Sounder calibrated by MOZAIC, Atmos. Chem. Phys., 12, 381-405, doi:10.5194/acp-12-381-2012, 2012.

McFarquhar, G. M. and Heymsfield, A. J.: Parameterization of tropical cirrus ice crystal size distribution and implications for radiative transfer: Results from CEPEX, J. Atmos. Sci., 54, 2187-2200, 1997.

Merino, F., Murtagh, D., Eriksson, P., Baron, P., Ricaud, P., and de La Noë, J.: Studies for the Odin sub-millimetre radiometer: 3. Performance simulations, Can. J. Phys., 80, 357-373, 2002.

Millán, L., Read, W., Kasai, Y., Lambert, A., Livesey, N., Mendrok, J., Sagawa, H., Sano, T., Shiotani, M., and Wu, D. L.: SMILES ice cloud products, J. Geophys. Res., 118, 6468-6477, doi:10.1002/jgrd.50322, 2013.

Murtagh, D., Frisk, U., Merino, F., Ridal, M., Jonsson, A., Stegman, J., Witt, G., Eriksson, P., Jiménez, C., Megie, G., de La Noë, J., Ricaud, P., Baron, P., Pardo, J. R., Hauchcorne, A., Llewellyn, E. J., Degenstein, D. A., Gattinger, R. L., Lloyd, N. D., Evans, W. F. J., McDade, I. C., Haley, C., Sioris, C., von Savigny, C., Solheim, B. H., McConnell, J. C., Strong, K., Richardson, E. H., Leppelmeier, G. W., Kyrölä, E., Auvinen, H., and Oikarinen, L.: An overview of the Odin atmospheric mission, Can. J. Phys., 80, 309-319, 2002.

Ochiai, S., Kikuchi, K., Nishibori, T., Manabe, T., Ozeki, H., Mizobuchi, S., and Irimajiri, Y.: Receiver performance of the Superconducting Submillimeter-Wave Limb-Emission Sounder (SMILES) on the International Space Station, IEEE Geosci. Re- 
mote Sens., 51, 3791-3802, doi:10.1109/TGRS.2012.2227758, 2013.

Petty, G. W. and Li, K.: Improved passive microwave retrievals of rain rate over land and ocean. Part I: Algorithm description, J. Atmos. Ocean. Tech., 30, 2493-2508, doi:10.1175/JTECH-D-1200144.1, 2013.

Read, W. G., Lambert, A., Bacmeister, J., Cofield, R. E., Christensen, L. E., Cuddy, D. T., Daffer, W. H., Drouin, B. J., Fetzer, E., Froidevaux, L., Fuller, R., Herman, R., Jarnot, R. F., Jiang, J. H., Jiang, Y. B., Kelly, K., Knosp, B. W., nd N. J. Livesey, J. J. K., Liu, H.-C., Manney, G. L., Pickett, H. M., Pumphrey, H. C., Rosenlof, K. H., Sabounchi, X., Santee, M. L., Schwartz, M. J., Snyder, W. V., Stek, P. C., Su, H., Takacs, L. L., Thurstans, R. P., Vömel, H., Wagner, P. A., Waters, J. W., Webster, C. R., Weinstock, E. M., and Wu, D. L.: Aura Microwave Limb Sounder upper tropospheric and lower stratospheric $\mathrm{H}_{2} \mathrm{O}$ and relative humidity with respect to ice validation, J. Geophys. Res., 112, D24S35, doi:10.1029/2007JD008752, 2007.

Rydberg, B., Eriksson, P., Buehler, S. A., and Murtagh, D. P.: NonGaussian Bayesian retrieval of tropical upper tropospheric cloud ice and water vapour from Odin-SMR measurements, Atmos. Meas. Tech., 2, 621-637, doi:10.5194/amt-2-621-2009, 2009.

Stephens, G. L., Vane, D. G., Boain, R. J., Mace, G. G., Sassen, K., Wang, Z., Illingworth, A. J., O'Connor, E. J., Rossow, W. B., Durden, S. L., Miller, S. D., Austin, R. T., Benedetti, A., Mitrescu, C., and the CloudSat Science Team: The CloudSat mission and the A-train, B. Am. Meteorol. Soc., 83, 1771-1790, 2002.

Takahashi, C., Ochiai, S., and Suzuki, M.: Operational retrieval algorithms for JEM/SMILES level 2 data processing system, J. Quant. Spectrosc. Ra. Transfer, 111, 160-173, 2010.

Tompkins, A. M., Gierens, K., and Rädel, G.: Ice supersaturation in the ECMWF integrated forecast system, Q. J. Roy. Meteorol. Soc., 133, 53-63, 2007.

Venema, V., Ament, F., and Simmer, C.: A Stochastic Iterative Amplitude Adjusted Fourier Transform algorithm with improved accuracy, Nonlin. Processes Geophys., 13, 321-328, doi:10.5194/npg-13-321-2006, 2006.

Waliser, D. E., Li, J.-L. F., Woods, C. P., Austin, R. T., Bacmeister, J., Chern, J., Genio, A. D., Jiang, J. H., Kuang, Z., Meng, H., Minnis, P., Platnick, S., Rossow, W. B., Stephens, G. L., SunMack, S., Tao, W.-K., Tompkins, A. M., Vane, D. G., Walker, C., and Wu, D.: Cloud ice: A climate model challenge with signs and expectations of progress, J. Geophys. Res., 114, D00A21, doi:10.1029/2008JD010015, 2009.
Waters, J. W., Froidevaux, L., Harwood, R. S., Jarnot, R. F., Pickett, H. M., Read, W., Siegel, P. H., Cofield, R. E., Filipiak, M. J., Flower, D. A., Holden, J. R., Lau, G. K., Livesey, N. J., Manney, G. L., Pumphrey, H. C., Santee, M. L., Wu, W. L., Cuddy, D. T., Lay, R. R., Loo, M. S., Perun, V. S., Schwartz, M. J., Stek, P., Thurstans, R. P., Boyles, M. A., Chandra, K. M., Chavez, M. C., Chen, G. S., Chudasama, B. V., Dodge, R., Fuller, R. A., Girard, M. A., Jiang, J. H., Jiang, Y. B., Knosp, B. W., LaBelle, R., Lam, J. C., Lee, K. A., Miller, D., Oswald, J. E., Patel, N. C., Pukala, D. M., Quintero, O., Scaff, D. M., Snyder, W. V., Tope, M. C., Wagner, P., and Walch, M. J.: The Earth Observing System Microwave Limb Sounder (EOS MLS) on the Aura satellite, IEEE T. Geosci. Remote, 44, 1075-1092, 2006.

Wu, D. L., Read, W. G., Dessler, A. E., Sherwood, S. C., and Jiang, J. H.: UARS/MLS cloud ice measurements: Implications for $\mathrm{H}_{2} \mathrm{O}$ transport near the tropopause, J. Atmos. Sci., 62, 518-530, doi:10.1175/JAS-3382.1, 2005.

Wu, D. L., Jiang, J. H., and Davis, C.: EOS MLS cloud ice measurements and cloudy-sky radiative transfer model, IEEE T. Geosci. Remote, 44, 1156-1165, 2006.

Wu, D. L., Jiang, J. H., Read, W. G., Austin, R. T., Davis, C. P., Lambert, A., Stephens, G. L., Vane, D. G., and Waters, J. W.: Validation of the Aurs MLS cloud ice water content measurements, J. Geophys. Res., 113, D15S10, doi:10.1029/2007JD008931, 2008.

Wu, D. L., Austin, R. T., Deng, M., Durden, S. L., Heymsfield, A. J., Jiang, J. H., Lambert, A., Li, J.-L., Livesey, N. J., McFarquhar, G. M., Pittman, J. V., Stephens, G. L., Tanelli, S., Vane, D. G., and Waliser, D. E.: Comparisons of global cloud ice from MLS, CloudSat, and correlative data sets, J. Geophys. Res., 114, D00A24, doi:10.1029/2008JD009946, 2009.

Wu, D. L., Lambert, A., Read, W. G., Eriksson, P., and Gong, J.: MLS and CALIOP cloud ice measurements in the upper troposphere: A constraint from microwave on cloud microphysics, J. Appl. Meteorol. Clim., 53, 157-165, doi:10.1175/JAMC-D-13041.1, 2014. 